\title{
DIRECT INJECTION AND SPARK CONTROLLED JET IGNITION TO CONVERT A DIESEL TRUCK ENGINE TO LPG
}

\author{
Alberto A. Boretti \\ School of Science and Engineering, University of Ballarat, Victoria, Australia
}

Copyright (C) 2010 SAE International

\begin{abstract}
Jet ignition and direct fuel injection are potential enablers of higher efficiency, cleaner Internal Combustion Engines (ICE). Very lean mixtures of gaseous fuels could be burned with pollutants formation below Euro 6 levels (in the ultra-lean mode), efficiencies approaching 50\% full load and small efficiency penalties when operating part load. The lean burn Direct Injection Jet Ignition (DI-JI) ICE uses a fuel injection and mixture ignition system comprising one main chamber direct fuel injector and one small size jet ignition pre-chamber per engine cylinder. The jet ignition pre-chamber is connected to the main chamber through calibrated orifices and accommodates a second direct fuel injector. In the spark plug version, the jet ignition pre-chamber includes a spark plug that ignites the slightly rich pre-chamber mixture that then bulk ignites the ultra lean, stratified main chamber mixture through multiple jets of hot reacting gases entering the in-cylinder. This paper uses coupled CAE and CFD simulations to provide better details of the operation of the jet ignition pre-chamber. They have been analysed so far with downstream experiments or standalone CFD simulations, enabling a better understanding of the complex interactions between chemistry and turbulence that governs the pre-chamber flow and combustion. CAE simulations are performed for a production 11 litre, in-line six, 24 valve Diesel Truck engine. It is turbo charged, with inter cooler and cooled Exhaust Gas Recirculation (EGR). It is modified to fit the jet ignition pre-chamber and run propane fuel by replacing the Diesel fuel injector with a direct injector for the LPG fuel plus reducing the compression ratio and changing the piston shape. Operation full load with same air-to-fuel equivalence ratio $\lambda=1.55$ is considered first. The load of the DI-JI LPG engine is then reduced by reducing the quantity of fuel injected Diesel like. The DI-JI LPG engine shows better than Diesel full and part load performances.
\end{abstract}

\section{INTRODUCTION}

Development of more energy-efficient and environmentally friendly highway transportation technologies based on Heavy Duty Truck (HDT) gas engines is a key factor for reducing fuel consumption, $\mathrm{CO}_{2}$ production and pollutants emissions within Australia. Providing improved national energy security, environment, and economy. Up until the early 1960s, railways dominated all but the shortest land-based freight task. Since then, vast improvements in road vehicle productivity, road infrastructure quality, the gradual removal of regulations restricting road freight carriage and the exponential growth in interstate trade has broadened the range of freight tasks for which road is better suited than rail. The Australian domestic freight task measured 521 billion tons kilometres in 2007, with 35\% carried by road [1]. Road trains cover the most part of interstate traffic. Australia has the largest and heaviest road vehicles in the world, with some configurations topping out at close to 200 tones. Two-trailer road trains, or B-doubles, are allowed in most parts of Australia, with the exception of some urban areas. Three trailer road trains or B-triples operate in western New South Wales, western Queensland, South Australia, Western Australia and the Northern Territory. The last three states also allow AB-Quads (3.5 trailers). Road trains are used for transporting all manner of materials. Their cost-effective transport has played a significant part in the economic development of remote areas, with some communities totally reliant on a regular service.

The domestic freight task has doubled in size over the past 20 years, with an averaging growth of 3.5\% per annum. BITRE (the Australian Government's Bureau of Infrastructure, Transport and Regional Economics) projections [1] suggest this trend will continue, although with slightly slower growth into the future, growing by approximately $3.0 \%$ per annum until 2030 . Over this period, road freight volumes are projected to more than double, with domestic demand for manufactured goods sustaining much of the growth, even if .the global financial crisis will certainly dampen freight growth in the near term. Australia's annual green house gases emissions through to the 2009 June quarter for energy - transport were $89 \mathrm{Mt} \mathrm{CO}_{2}$-e [2], or about the $14.5 \%$ of the total.

Life-cycle Emissions Analysis of Alternative Fuels for Heavy Vehicles [3 and 4] has shown the potential of gaseous fuels for heavy duty trucks. There have been major advances in natural gas engines in recent years so the present generation of natural gas vehicles has significantly lower emissions than the present generation of Diesel vehicles. The emissions based on use in Original Equipment 
Manufacture (OEM) vehicles are lower in all categories, greenhouse gases, important criteria pollutants, and air toxics. Lower particulate emissions and noise levels compared with Diesel make gas particularly attractive for urban areas. The major uncertainty relates to upstream and in-service leakage, however already sufficiently reduced in the present generation of OEM natural gas vehicles, and insufficient refuelling stations. The extra weight of CNG fuel tanks leads to slightly higher fuel consumption, or lower payload in buses. This is less of a problem with LNG vehicles due to the higher energy density. Similarly, a dedicated LPG bus produces significantly lower emissions of important criteria pollutants, and lower exbodied emissions of greenhouse gases than Diesel. Air toxics from tailpipe emissions of LPG vehicles are much lower than those of Diesel vehicles, but the greater upstream processing emissions of air toxics results in the exbodied emissions of air toxics from LPG being much the same as those from Diesel.

LPG, the commercially available propane fuel for transport, is not pure propane [38]. In the USA and Canada, it is primarily propane (minimum 90\%), with the rest mostly butane and propylene (5\% maximum), plus odorants as per the HD5 (Heavy Duty 5\% maximum allowable propylene content) standard. Not all the products labelled LPG worldwide conform to this standard. While LPGHD5 has a minimum propane content of $90 \%$, the ratio of propane and butane varies widely in LPG-Auto-gas. LPG-HD5 emits more $\mathrm{NO}_{\mathrm{x}}$ but less particulate matter than LPG-Auto-gas, while emissions of hydrocarbons are similar. The main benefit of LPG-HD5 when compared with LPG-Auto-gas is that the compression ratio can be altered to suit the higher-octane number. Table A1 in Appendix presents Motor Octane Number (MON) and Research Octane Number (RON) of LPG components. Australian standards for LPG-Auto-gas prescribe a minimum Motor Octane Number (MON) of 90.5, to be possibly reduced to 89 [39 and 40]. LPG-HD5 has a pump octane number (the average of MON and RON) much closer to the one of propane of 105 [41]. The lower particulate emissions and lower noise levels compared with Diesel make LPG attractive for use in urban areas. The major disadvantage of LPG is the lack of market penetration of dedicated heavy LPG vehicles. The main properties of gasoline, propane, ethanol and methanol fuels are presented in Table 1. Table A2 in Appendix. Ethanol, methanol and propane are the most promising candidates to replace gasoline in spark ignition engines.

Improving the efficiency of internal combustion engines is the most promising and cost-effective approach to increasing vehicle fuel economy in the next 10 to 20 years, or until such time still far to forecast when plug-in hybrid electric or fuel cell hybrid vehicles will dominate the market [5]. Advanced combustion engines have still great potential for achieving dramatic energy efficiency improvements in heavy-duty vehicle applications. The primary hurdles that must be overcome to realize increased use of advanced combustion engines are the higher cost of these engines which still require expensive R\&D when compared to conventional engines and compliance with particularly stringent new emission regulations where the catalytic emission control technologies are much less mature than gasoline engine catalysts.

Australian Design Rule (ADR) 80/03 requires compliance with Euro 5 standards for heavy duty trucks starting 1 January 2010 for new model vehicles and 1 January 2011 for all produced vehicles sold new. Near future regulations will very likely follow Euro 6 standards. Euro 6 regulation proposal will introduce particularly tough emission standards [6]. Procedure provisions will be defined for test cycles, off cycle emissions, particulate number $(\mathrm{PN})$, emissions at idling speed, smoke opacity, possible introduction of $\mathrm{NO}_{2}$ emission limit, correct functioning and regeneration of pollution control devices, crankcase emissions, On board diagnostic (OBD) systems and in-service performance of pollution control devices, durability, portable emission measurement system (PEMS) to verify in-use emissions, $\mathrm{CO}_{2}$ and fuel consumption, measurement of engine power, reference fuels, specific provisions to ensure correct operation of $\mathrm{NO}_{\mathrm{x}}$ control measures. Implementation of these stringent emission standards is anticipated to cause a reduction in fuel efficiency due to the exhaust emission control devices needed to meet emissions regulations for both $\mathrm{NO}_{\mathrm{x}}$ and $\mathrm{PM}$ without introduction of advanced combustion technologies.

Advanced combustion engine technologies being developed by the Author [7-8, 15-20, 36, 37] are focused on internal combustion engines (ICE) fuelled with gaseous fuels, operating in advanced combustion regimes, including modes of low-temperature combustion (LTC), which increase efficiency beyond current advanced Diesel engines and reduce engine-out emissions of nitrogen oxides $\left(\mathrm{NO}_{\mathrm{x}}\right)$ and particulate matter $(\mathrm{PM})$ to near-zero levels. In addition to advanced combustion regimes, reduction of heat transfer, control of load by quantity of fuel injected and a wide range of waste heat recovery technologies are also being considered to further improve engine efficiency and reduce fuel consumption.

Current heavy-duty Diesel engines have efficiencies in the range of $42-43 \%$. Improvements in a wide variety of engine components such as boosting, thermal management, and recovery of rejected thermal energy are expected to enable efficiencies to reach $50 \%$ if aggressive R\&D is able to proceed [5]. More stringent emission regulations may reduce efficiency and increase fuel consumption. Technical Targets for Heavy Truck Diesel Engines [5] in year 2013 are prototypes delivering Engine thermal efficiency of 55\% and NOx and PM emissions using 15-ppm sulphur Diesel fuel of less than 0.2 and less than $0.01 \mathrm{~g} / \mathrm{bhp}$-hr respectively. With gaseous fuels, certainly much less aggressive R\&D seems needed to produce efficiencies around 50\% using always lean burn technologies.

\section{BENEFITS OF DIRECT INJECTION AND JET IGNITION}

The lean burn Direct Injection Jet Ignition (DI-JI) engine is an Internal Combustion Engine (ICE) developed to more efficiently and completely burn gaseous and liquid fuels within the cylinder of a four stroke engine. This engine uses a fuel injection and mixture ignition system comprising one main chamber DI fuel injector and one jet ignition pre-chamber per engine cylinder. The system is 
aimed to increase top brake efficiencies and reduce the efficiency penalty from changing the load for a Diesel-like operation by quantity of fuel injected enabled by the option to burn fuel mixtures extremely lean.

The small size jet ignition pre-chamber is connected to the main chamber through calibrated orifices and accommodates another DI fuel injector. In the spark plug version, the pre-chamber also accommodates a spark plug that ignites a pre-chamber mixture slightly rich that then bulk ignites the ultra lean, stratified main chamber mixture through the multiple jets of hot reacting gases entering the in-cylinder [7].

Figure 1 present a sectional view of an engine fitted with the direct injection jet ignition engine concept. The engine layout has same complexity of a gasoline direct injection engine for lean stratified combustion with central spark plug and fuel injector, because the jet ignition device may be designed as a component replacing the $\Phi=14 \mathrm{~mm}$ thread standard spark plug [17-20, 46]. The main chamber injector is located at the centre of the combustion chamber close to the pre-chamber nozzles. The jet ignition pre-chamber has 6 nozzles. It accommodates one racing spark plug $\Phi=10 \mathrm{~mm}$ [21] and one pre-chamber injector. It features 6 equally spaced nozzles of diameter $\Phi=1.25 \mathrm{~mm}$. The total pre-chamber volume is less than $1.5 \mathrm{~cm}^{3}$.

The fuel injection and mixture ignition system operates as follows. The main fuel is injected directly within the cylinder by a main chamber DI injector operating one single or multiple injections to produce a lean stratified mixture preferably in the bulk. This non homogeneous mixture is mildly lean in an inner region surrounded by air and some residuals from the previous cycle. The extension of the inner region may be reduced in size to achieve mean chamber average mixtures ranging from slightly lean to extremely lean. Computational experiences made so far have been realized with equivalent air-to-fuel ratios $\lambda=1$ to $\lambda=6.6$ [15-20, 36, 37]. This mixture is then ignited by one or more jets of reacting gases that issue from the small pre-chamber connected to the main chamber via calibrated orifices, sourced from the same or an alternative fuel that is injected into it by a second DI injector and then ignited by the spark plug discharge. Combustion started slightly fuel rich in the very small volume pre-chamber then moves very fast to the main chamber through the one or more nozzles, with one or more jets of hot reacting gases bulk igniting the main chamber mixture. The jets of reacting gases enhance combustion of lean stratified mixtures within the main chamber through a combination of large thermal energy, multiple ignition points and presence of active radical species. Prior simulations and experiments jet igniting homogeneous charges of hydrocarbon fuels have shown the opportunity to achieve very fast combustion rates with reduced formation of HC and $\mathrm{CO}$ even running very lean [24-30]. Lean stratified mixtures are expected to further enhance the always lean burn option enabled by jet ignition.

With reference to the homogeneous DI or PFI and the main chamber spark ignition, non homogeneous DI and jet ignition offer the advantage of much faster, more complete, much leaner combustion, less sensitivity to mixture state and composition, reduced heat losses to the main chamber walls. This is because of the better fuel distribution for the same main chamber averaged fuel-to-air equivalence ratio lean conditions, combustion in the bulk of the in cylinder gases, a heat transfer cushion of air between hot reacting gases and walls, the availability of very high ignition energy at multiple simultaneous ignition sites igniting the bulk of the in cylinder gases and the start of main chamber combustion aided by large concentrations of partially oxidized combustion products initiated in the pre-chamber that accelerate the oxidation of fresh reactants within the main chamber.

Advantages of the system are larger brake efficiency (ratio of engine brake power to total fuel energy) and therefore reduced brake specific fuel consumption (ratio of engine fuel flow rate to brake power), resulting in improved full load operation of stationary and transport engines, efficient combustion of variable quality fuel mixtures from close to stoichiometry to extremely lean for load control mostly throttle less by quantity of fuel injected for improved part load operation of non stationary engines, and the opportunity in the ultra lean mode to produce near zero $\mathrm{NO}_{\mathrm{x}}$ in addition to the nearly zero particulate with gaseous fuels [15-20, 36, 37].

Jet ignition and direct fuel injection are potential enablers of higher efficiency, cleaner Internal Combustion Engines (ICE), where very lean mixtures of gaseous fuels could be burned with pollutants formation below Euro 6 levels and efficiencies approaching 50\% full load and small efficiency penalties operating part load.

The concept proposed in the paper - coupling of direct injection of main chamber fuel and bulk ignition by multiple jet of hot gases from a very small size pre-chamber fitted with a second fuel injector and a spark plug - has been covered by papers and patents only by researchers of the group of Professor Harry Charles Watson at the University of Melbourne and by the Author of this paper [7-8, 15-20, 24-30, 36 and 37]. The concept is an original evolution of the idea of using jet-style ignition to enable the operation of a flame-propagation engine with very lean mixtures explored many times, mostly in the large engine natural gas industry, with remarkable differences from the direct injector to the main chamber creating there mixtures from lean homogeneous to lean stratified to explore the many options of low temperature combustion, and the very small size pre-chamber fitted with a second fuel injector and a spark plug enabling start of combustion by multiple jet of hot reacting gases originating from an almost stoichiometric ignition of a small fraction of the total fuel.

The small size of the pre-chamber $\left(1.5 \mathrm{~cm}^{3}\right.$ connected to an $1800 \mathrm{~cm}^{3}$ displaced in cylinder volume of the 11 litre truck engine considered in the applications) accepting a very small percentage of the total fuel injected is supposed to keep low $\mathrm{NO}_{\mathrm{x}}$ production. This is a major limitation of traditional pre-chamber engines even at very lean operating conditions. The jet ignition device was 
originally intended to replace a standard $14 \mathrm{~mm}$ thread spark plug in port fuel injected engines with lean premixed combustion [2430]. Minimum development investments could allow production of miniaturized jet ignition devices the same size as a traditional spark plug with better opportunity for the technology to be applied to existing engine layouts.

Spark plug life within the pre-chamber is generally not viewed as a major issue so long as cooling needs are included when designing the pre-chamber housing. However, the limited amount of space available to accommodate a spark plug and the resulting very far from optimal conditions may suggest replacement of a spark plug with a much smaller glow plug [8, 36 and 37]. In the glow plug version of the ignition pre-chamber, the spark plug is replaced by a glow plug [34] not only to increase durability and reduce maintenance costs, but also increase packaging and avoid occurrence of locally fuel rich conditions to control auto ignition and prechamber injection. On the other hand the operation of the glow plug pre-chamber is on the other hand much more complicated, and some additional studies are needed to further develop the concept. The direct injection jet ignition engine conception is therefore a novel idea, of particular relevance for gaseous fuels, and definitely has potentials for further interesting studies and developments.

\section{PRECHAMBER AND INJECTORS DATA}

If $\mathrm{V}_{\mathrm{PC}}$ is the pre-chamber volume, $\mathrm{V}_{\mathrm{MCC}}$ is the main chamber combustion chamber volume and $\mathrm{V}_{\mathrm{D}}$ the displaced volume $\left(\mathrm{V}_{\mathrm{D}}=\pi \cdot \mathrm{B}^{2} / 4 \cdot \mathrm{S}\right.$, with $\mathrm{B}$ bore and $\mathrm{S}$ stroke), the true compression ratio is:

$C R=\frac{V_{P C}+V_{M C C}+V_{D}}{V_{P C}+V_{M C C}}$

While the reference compression ratio is:

$C R^{*}=\frac{V_{M C C}+V_{D}}{V_{M C C}}$

If $\eta_{\mathrm{V}}$ is the volumetric efficiency:

$\eta_{V}=\frac{m_{a}}{\rho_{a, i} \cdot V_{D}}$

Where $m_{a}$ is the mass of air trapped within the cylinder when the intake valves close and $\rho_{a, i}$ is the reference air density, then the mass of fuel to be injected within the pre-chamber is:

$m_{f_{, P C}}=\left[\frac{\left(f / a_{, s}\right)}{\lambda_{P C}}\right] \cdot \eta_{V} \cdot \rho_{a, i} \cdot(C R-1) \cdot V_{P C}$

While the quantity of fuel to be injected within the main chamber is

$m_{f_{, M C}}=\left[\frac{\left(f / a_{, s}\right)}{\lambda_{M C}}\right] \cdot \eta_{V} \cdot \rho_{a, i} \cdot\left[V_{D}-(C R-1) \cdot V_{P C}\right]$

where ( $\left.\mathrm{f} / \mathrm{a}_{\mathrm{s}}\right)$ is the stoichiometric fuel to air ratio ( 0.0642 for propane $\mathrm{C}_{3} \mathrm{H}_{8}, 0.0584$ for methane $\mathrm{CH}_{4}$ and 0.0294 for hydrogen $\mathrm{H}_{2}$ ), $\lambda_{\mathrm{PC}}$ the pre-chamber operational air to fuel equivalence ratio (slightly smaller than unity) and $\lambda_{\mathrm{MC}}$ the main chamber operational air to fuel equivalence ratio much larger than unity $\left(2.5\right.$ to 6.6 to cover the full load range with negligible production of $\left.\mathrm{NO}_{\mathrm{x}}\right)$. $\eta_{\mathrm{V}}$ is about one for naturally aspirated engines, but can reach values up to 2.5 in highly turbocharged versions with charge cooler, thanks to the recovery of the exhaust energy.

From previous relations, the main chamber DI injector has to deliver much larger quantities of fuel than the pre-chamber DI injector. Injection pressures requested are 200-300 bar for the High Pressure (HP) main chamber DI injector, and 25-50 bar for the Low Pressure (LP) pre-chamber DI injector. In the case of the four cylinders, 1.5 litre, turbocharged engine, with volumetric efficiencies approaching $\eta_{\mathrm{V}}=2$, the amount of $\mathrm{C}_{3} \mathrm{H}_{8}$ and $\mathrm{CH}_{4}$ fuels introduced within the main chamber are about 24.5-12.25 mg and 22.5-11.25 $\mathrm{mg}$ respectively when running with $\lambda_{\mathrm{MC}}=2.25-4.5$. Conversely, the amount of fuel introduced within the pre-chamber is roughly 2.8 and $2.6 \mathrm{mg}$ respectively with $\mathrm{C}_{3} \mathrm{H}_{8}$ and $\mathrm{CH}_{4}$ fuels, i.e. $10-20 \%$ of the main chamber fuel.

Injectors are preferably of the multi holes type and if possible operate with chocked flow through nozzles. Isobaric properties of propane, methane and hydrogen at 200 bar of pressure and temperatures 300-400 K [9] show propane is liquid 300-370 K, with 
densities $501-380 \mathrm{~kg} / \mathrm{m}^{3}$, then supercritical [9], while methane and hydrogen are always supercritical with much smaller densities $155.3-98.5 \mathrm{~kg} / \mathrm{m}^{3}$ and $14.4-11.06 \mathrm{~kg} / \mathrm{m}^{3}$ respectively. Isobaric properties of propane, methane and hydrogen at 50 bar of pressure and same temperatures show propane is liquid 300-370 K, with densities $531-450 \mathrm{~kg} / \mathrm{m}^{3}$, then supercritical [9], while methane and hydrogen are always supercritical with much smaller densities $35-24.6 \mathrm{~kg} / \mathrm{m}^{3}$ and $3.43-2.96 \mathrm{~kg} / \mathrm{m}^{3}$ respectively. Despite the speed of sound being larger in hydrogen than methane and propane, respectively $1318.4 \mathrm{~m} / \mathrm{s}$ for hydrogen, $449.5 \mathrm{~m} / \mathrm{s}$ for methane and 252.3 $\mathrm{m} / \mathrm{s}$ for propane at typical injection conditions, mass flow rates are smaller with hydrogen than methane than propane, thus requiring larger flow passages.

Ideally, main chamber and pre-chamber injections should complete approaching TDC, when the fast combustion process should start initiated by the spark discharge. The fast actuating, HP, high flow rate, main chamber DI injector must produce a bulk, lean, stratified mixture fully jet controlled or mixed jet/wall controlled and injection should occur with valves closed. Because of the load control by quantity of fuel injected, injection times may vary considerably running from lean $\lambda=2.5$ to extremely lean $\lambda=5$ and above. The LP, low flow rate, pre-chamber DI injector is in principle less demanding because it must introduce a smaller amount of fuel that does not change too much with load or speed without time constraints to produce slightly fuel rich conditions within the small $1.5 \mathrm{~cm}^{3}$ prechamber.

Prototype hardware has been defined so far using normal production injectors. However, better performances are possible by developing ad hoc solutions for both main chamber and pre-chamber DI injectors. Durability and dry run capability are not an issue in prototype applications. One last generation, fast actuating, HP GDI injector could be used as the main chamber injector for propane, for example one of the high pressure fast single coil or piezo GDI injectors proposed in [10, 11]. Conversely, a specific injector, for example the high pressure one proposed in [12], must be used for the short injection time, high temperature, high injection pressures, high durability and dry run capability with methane and more over with hydrogen.

The fast single coil DI injector in [10] provides (with gasoline fuel) flow rates up to $40 \mathrm{~g} / \mathrm{s}$ at 200 bar, up to 3 multiple injections, hydraulic separation at multiple injection $\leq 0.2 \mathrm{~ms}$, and a hollow cone pattern with cone angles as required by the application. The double acting multi holes DI injector in [12] has much larger areas, with equivalent flow areas of $0.7 \mathrm{~mm}^{2}$ through 16 holes, and may deliver up to $20 \mathrm{~g} / \mathrm{s}$ with methane at $200 \mathrm{bar}$, with response times within $0.1 \mathrm{~ms}$ and minimum injection duration $0.5 \mathrm{~ms}$. This latter injector has also been used with hydrogen in prototype applications [13].

The ignition pre-chamber is very small in size, just a few percents of the combustion chamber volume at Top Dead Centre (TDC) and about $1.5 \mathrm{~cm}^{3}$. The JI pre-chamber is designed to be fitted within the traditional spark plug thread $\Phi=14$ mm to only marginally increases the level of complexity of designing a cylinder head with a JI pre-chamber replacing the standard main chamber SP and allow testing on existing hardware. The $1-1.5 \mathrm{~cm}^{3}$ volume and the operation with a slightly fuel rich mixture are the ones that have provided so far the best results [24-30]. A standard LP GDI injector (for example the low pressure ones proposed in [11, 14]), can be used as the pre-chamber injector for prototype applications where again durability and dry run capability are not an issue with all the fuels.

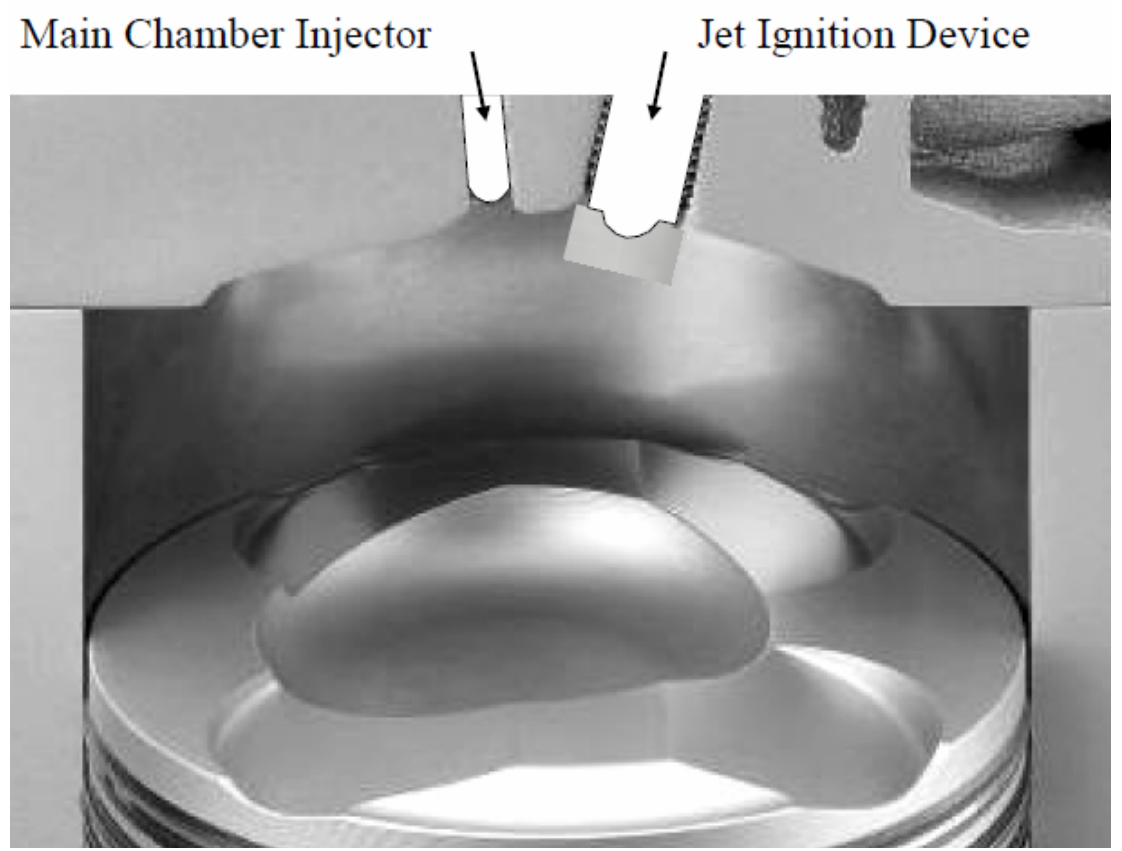

Figure 1 - Sectional view of the direct injection jet ignition engine.

The jets of reacting gases from the ignition pre-chamber then ignite the main chamber mixture. Diameters and number of nozzles control the flow of air (and residuals) from main chamber to pre-chamber during compression, and pre-chamber to main chamber 
during the jet ignition event, where the multiple jets of hot, reacting products must enter the main chamber with enough speed and energy to ignite the main chamber mixture. A configuration with 6 equally spaced nozzles of diameter $\Phi=1.25 \mathrm{~mm}$ is the one that has provided so far the best results [24-30] igniting homogeneous lean main chamber mixtures.

\section{PRIOR COMPUTATIONAL RESULTS}

Computations have been performed by using CFD and CAE tools. A CFD tool is used to simulate the detailed fluid dynamic and combustion of the standalone pre-chamber in $3 \mathrm{D}$, while a CAE tool is used to describe the full cyclic engine operation including in cylinder and pre-chamber. CFD simulations are performed by using STAR-CCM [21], while CAE simulations are performed by using GT-POWER [23] and WAVE [31]. GT-POWER and WAVE are the industry-standard CAE engine simulation tools, used by most leading engine and vehicle makers and their suppliers. STAR-CCM [22] is one of the most promising CFD platforms delivering the entire CFD process from CAD to post-processing in a single integrated software environment. Innovations such as built-in surfacewrapping and advanced automated meshing have quickly established STAR-CCM a reputation for producing high-quality results in a single code with minimum user effort. STAR-CCM features automatic meshing technology and a comprehensive selection of physics models delivering accurate solutions in an easy-to-use environment.

\section{D STANDALONE PRE-CHAMBER}

STAR-CCM simulations of combustion evolution have been performed for the standalone pre-chamber connected to a simplified main chamber where constant pressure boundary conditions can apply. Figure 2a presents a sectional view of the computational model of the ignition pre-chamber with fitted a multi-holes fuel injector. The spark plug is located top right, while the low pressure injector is located top left. The actual low pressure injector is replaced by a volume connected to the pre-chamber through multiple nozzles. Actual sac volume and diameter and length of nozzles are much smaller than those represented. An inlet velocity boundary condition is used at the top of the injection volume, while a pressure outlet condition is used along the spherical surface, while all the other boundaries are adiabatic solid walls. Ignition is started after injecting a slightly rich mixture of fuel within the pre-chamber. Initial conditions within the pre-chamber are high temperatures and pressures typical of engine operation at top dead centre.

The initial composition of the fluid within the domain is just air (no fuel downstream of the pre-chamber). The effect of a variable in cylinder volume downstream producing a very intense flow main chamber to pre-chamber through the connecting nozzles is neglected. The main goal of these computations is to determine how long it takes from spark discharge combustion initiation within the pre-chamber to get multiple jets of hot reacting products igniting the main chamber mixture. The mean and turbulent velocity field within the pre-chamber is underestimated, and therefore the turbulent transport and diffusion is also underestimated.

The flow is considered turbulent, compressible, reacting, multi species. Turbulence is modelled by using a k- $\varepsilon$ model with a two layer all $\mathrm{y}+$ wall treatment [22]. Combustion is represented through a 3 step Eddy Break-Up (EBU) [22] for propane of reactions:

1. $\mathrm{C}_{3} \mathrm{H}_{8}+1.5 \cdot \mathrm{O}_{2} \rightarrow 3 \cdot \mathrm{CO}+4 \cdot \mathrm{H}_{2}$

2. $\mathrm{CO}+1 / 2 \cdot \mathrm{O}_{2} \rightarrow \mathrm{CO}_{2}$

3. $\mathrm{H}_{2}+1 / 2 \cdot \mathrm{O}_{2} \rightarrow \mathrm{H}_{2} \mathrm{O}$

Ignition is started in the computational cells included in a small spherical volume in between the spark plug electrodes, where the fuel is prescribed to burn within a given time interval. After that, the EBU model computes the evolution of combustion from reactants and products concentration and turbulence mixing time [22]:

$$
R_{F}=-\frac{\rho}{M_{F}} \cdot\left(\frac{1}{\tau_{m i x}}\right) \cdot A_{e b u} \cdot \min \left(Y_{F}, \frac{Y_{O}}{S_{O}}, B_{e b u} \cdot\left(\frac{Y_{P_{1}}}{S_{P_{1}}}+\ldots+\frac{Y_{P_{j}}}{S_{P_{j}}}\right)\right]
$$

where $\tau_{\mathrm{R}}=\tau_{\text {mix }}$ and $\tau_{\text {mix }}=\mathrm{K} / \varepsilon$, with $\mathrm{K}$ the turbulent kinetic energy and $\varepsilon$ its dissipation rate. Two EBU coefficients are used for each equation. Standard values $\mathrm{A}_{\mathrm{ebu}}=4, \mathrm{~B}_{\mathrm{ebu}}=0.5$ are used for the EBU coefficients.

The previous expression does not account for chemical kinetics that may be relevant during ignition and describing the flame behaviour close to solid boundaries, where because the turbulent mixing time scale $\tau_{\text {mix }}$ decreases with decreasing the distance from solid surfaces, reaction rates are over predicted in near wall regions. The Hybrid Kinetics/EBU Model [22] accounts for finite rate effects by assuming that the actual reaction rate is the minimum from kinetics and turbulent mixing controlled reactions. The mixing time scale in the previous equation $\tau_{\mathrm{R}}$ is then augmented by a time scale derived from the chemical reaction rate from finite-rate kinetics $\tau_{\text {kin }}$ to avoid the near wall misrepresentation of flames. The Combined Time Scale Model [22] then assumes $\tau_{\mathrm{R}}=\tau_{\text {mix }}+\tau_{\mathrm{kin}}$, where $\tau_{\text {kin }}$ is computed by the kinetics model.

The computational grid, made up of just 100,000 polyhedral cells to keep the computational time and the internal memory requirements very low, below $400,000 \mathrm{~K}$ memory usage. Results of computations for $\mathrm{C}_{3} \mathrm{H}_{8}$ propane 0.1 ms after start of combustion (SOC), the time of the spark discharge, are presented in Figures $2 \mathrm{~b}$ to $2 \mathrm{~g}$ for temperature, $\mathrm{H}_{2}, \mathrm{H}_{2} \mathrm{O}, \mathrm{CO}_{2}, \mathrm{CO}$ and velocity. Hot products of combustion are travelling at high speed through the main chamber. In case of operation of the pre-chamber fitted on a 
cylinder head, these multiple jets would ignite the lean stratified mixture in the bulk of the in cylinder volume passing through regions with very little fuel available.

With methane, combustion kinetics is slower than propane, while with hydrogen combustion kinetics is faster. As previously stated, within the engine, the much larger turbulent field, the enhanced mixing of the downward injected fluid with the upward air flow from the main chamber, the heat transfer from the hot walls is expected to further reduce the time frame of the pre-chamber ignition phenomena. These CFD simulations of the standalone pre-chamber have been performed with methane, propane and hydrogen fuel to estimate the delay between start of combustion within the pre-chamber and sufficient penetration of the hot, partially burned, reacting gases within the main chamber. Delay times are larger with methane and smaller with hydrogen because of the different kinetics. As a general statement, we may assume these times to be something of the order of $0.1 \mathrm{~ms}$. The computed delay times will then be used as an input of CAE simulations of the full engine.

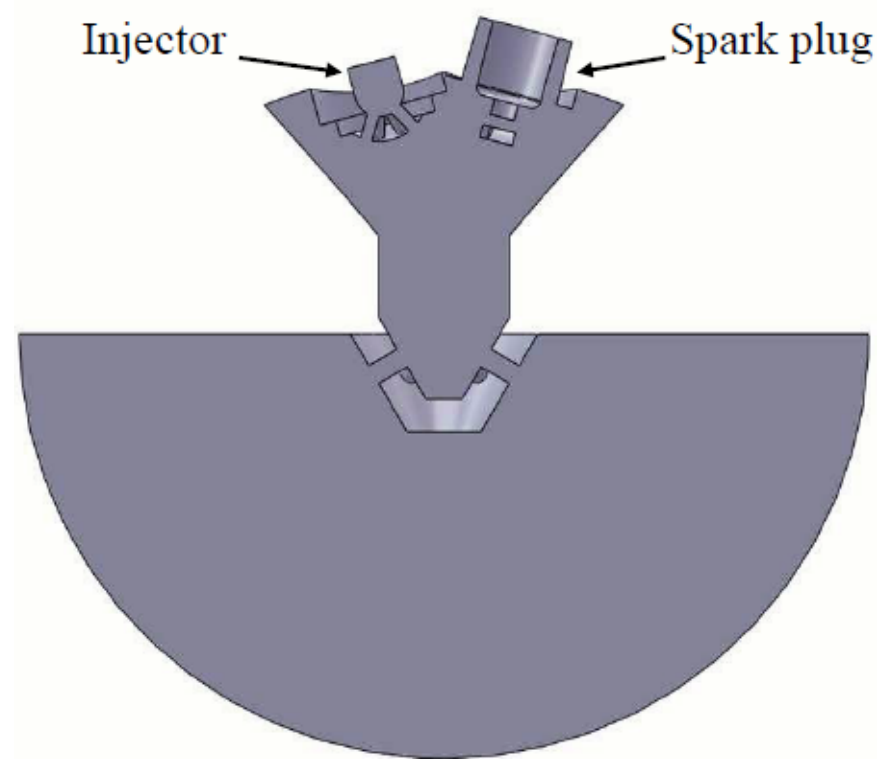

Figure $2 \mathrm{a}$ - Sectional view of the ignition pre-chamber connected to a downstream semi sphere.

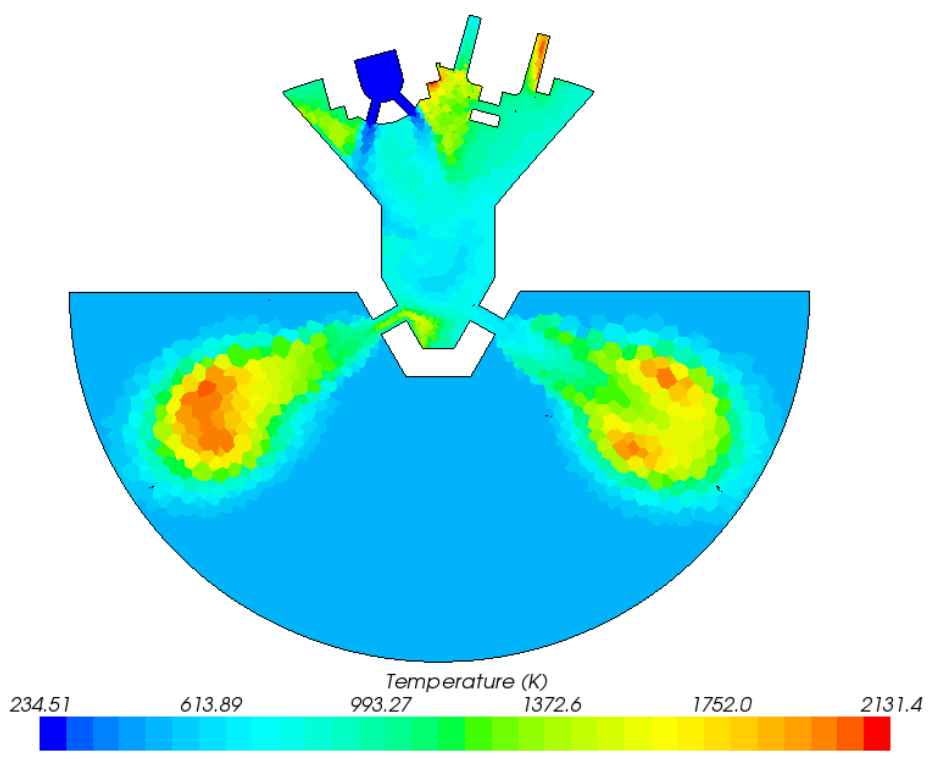

Figure $2 \mathrm{~b}$ - Computed temperature field $0.1 \mathrm{~ms}$ after SOC (propane) 


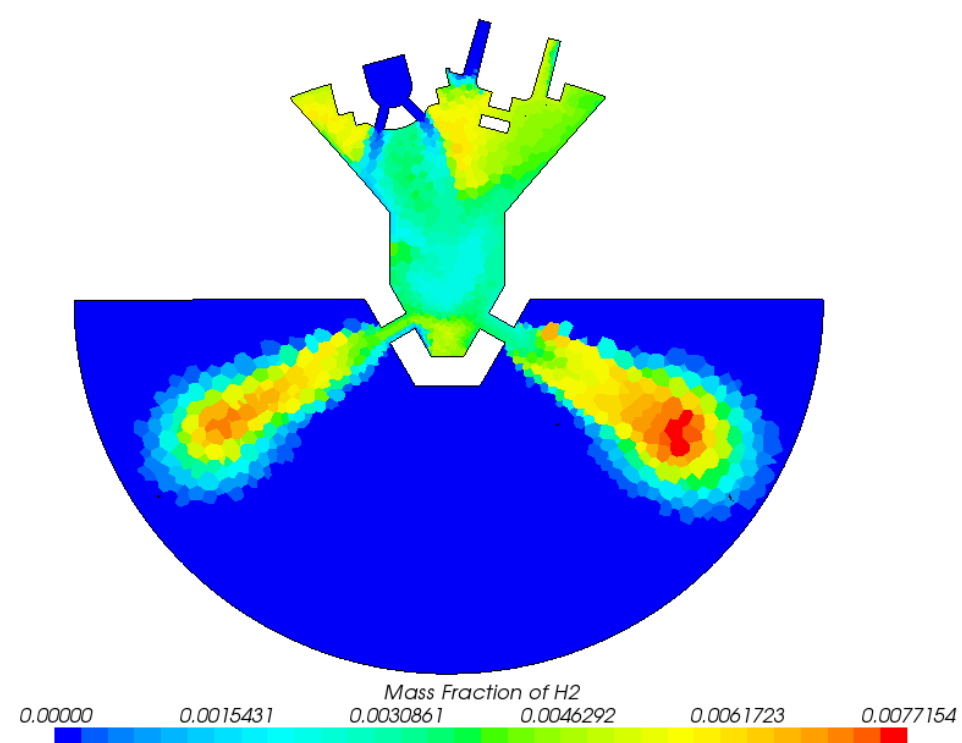

Figure 2c-Computed $\mathrm{H}_{2}$ field $0.1 \mathrm{~ms}$ after SOC (propane)

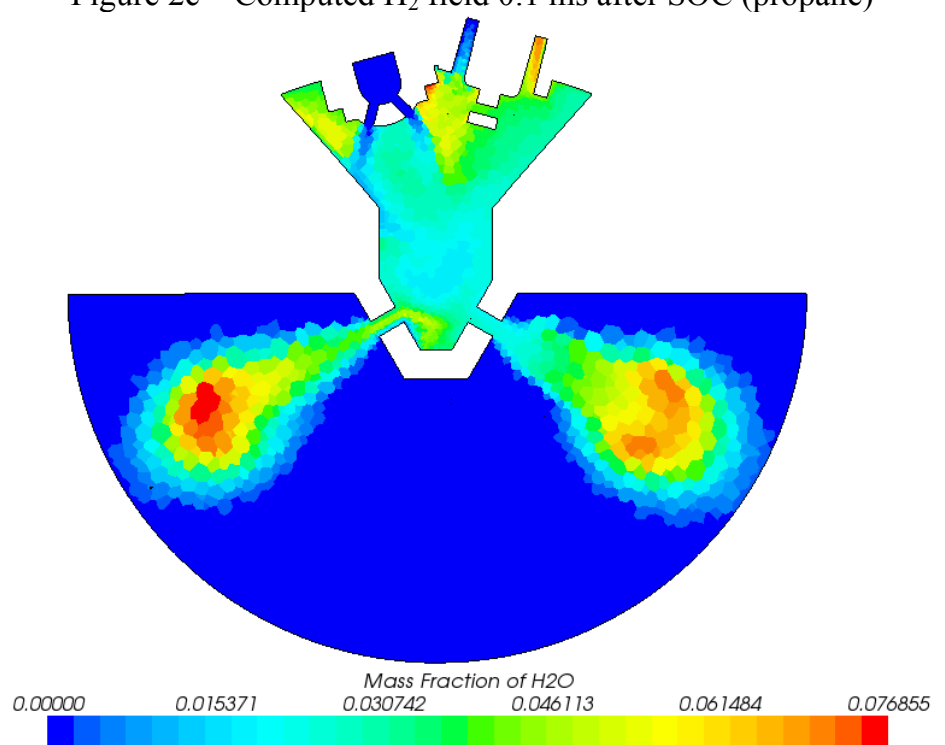

Figure $2 \mathrm{~d}$ - Computed $\mathrm{H}_{2} \mathrm{O}$ field $0.1 \mathrm{~ms}$ after SOC (propane)

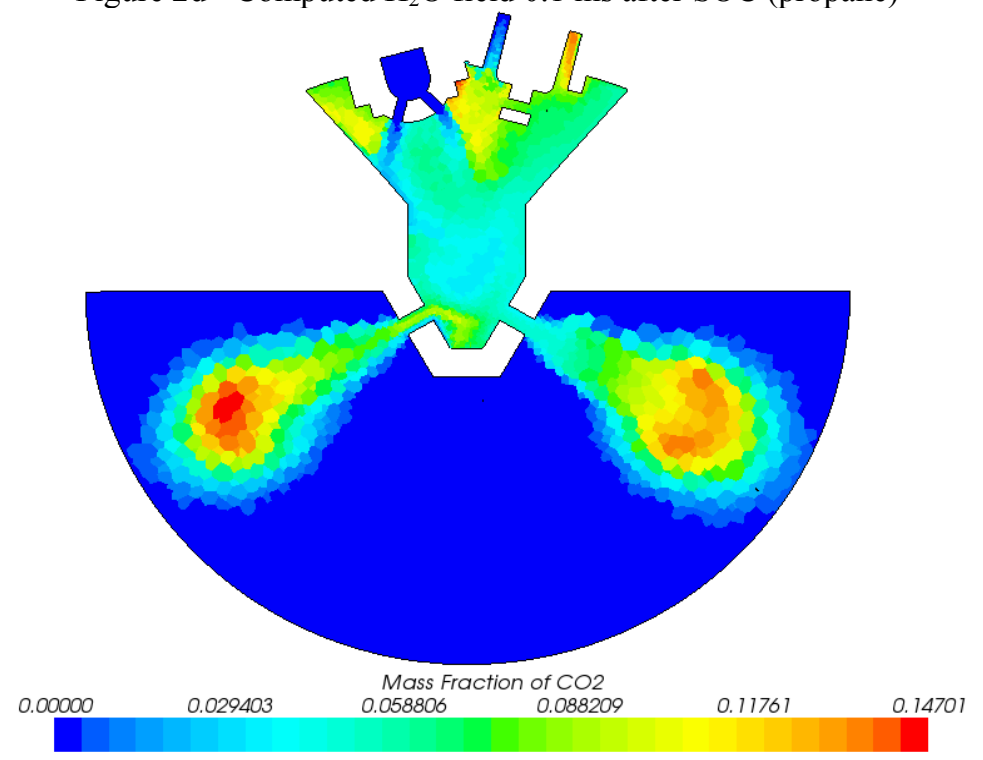

Figure $2 \mathrm{e}$ - Computed $\mathrm{CO}_{2}$ field $0.1 \mathrm{~ms}$ after SOC (propane) 


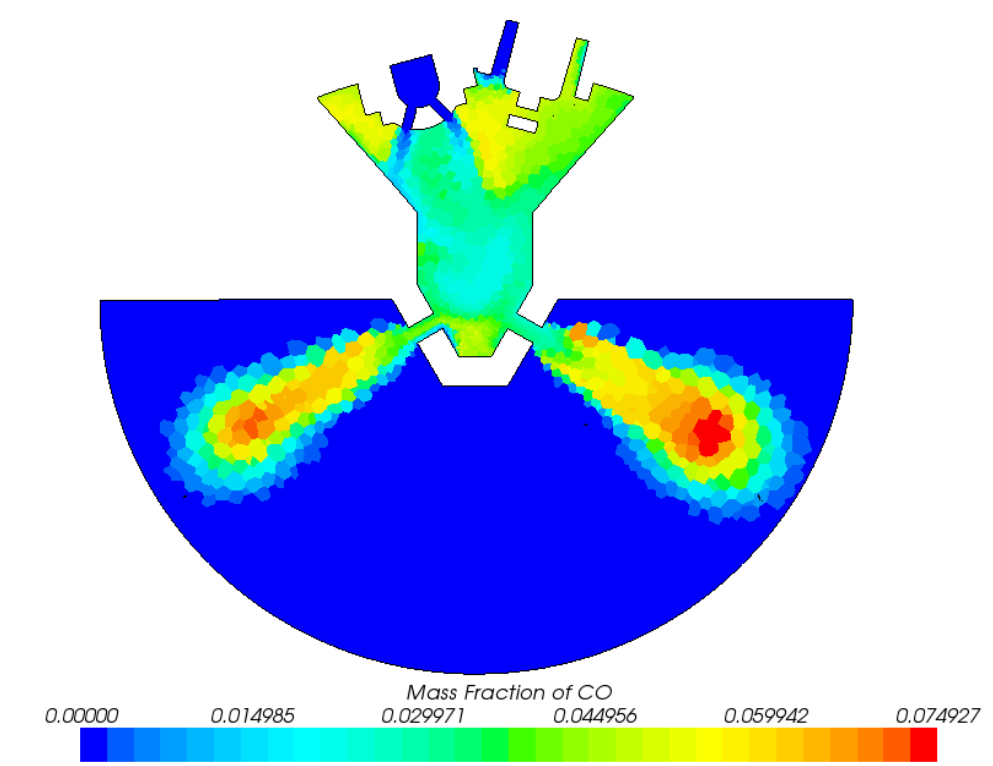

Figure $2 \mathrm{f}-$ Computed field of CO $0.1 \mathrm{~ms}$ after SOC (propane)

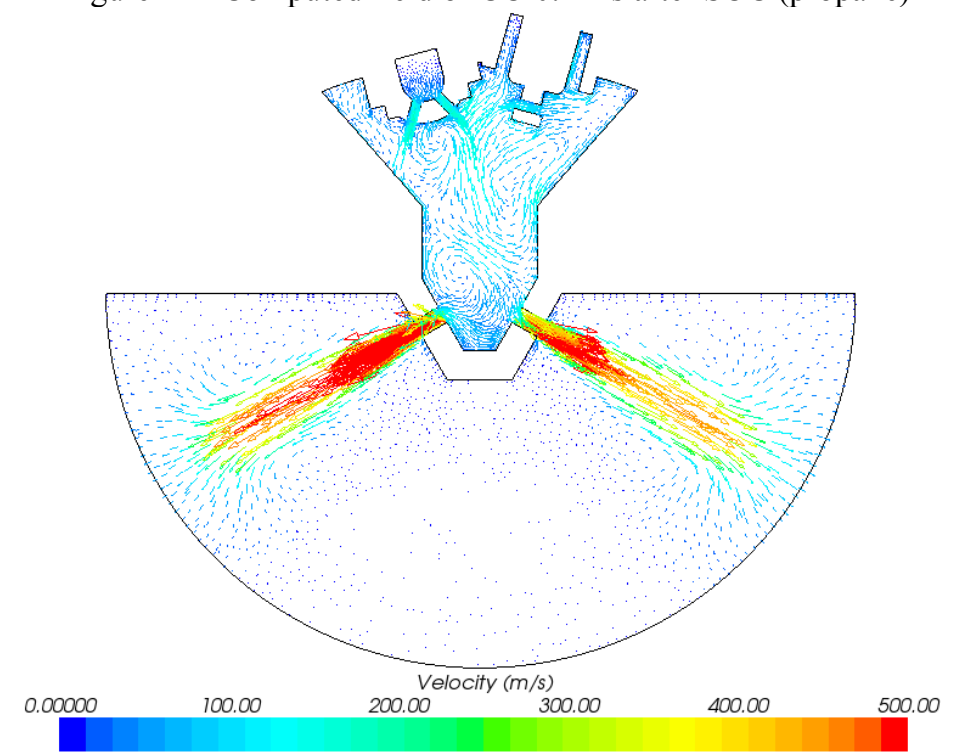

Figure $2 \mathrm{~g}$ - Computed velocity field $0.1 \mathrm{~ms}$ after start SOC (propane)

CFD simulations of the standalone pre-chamber may help in the definition of the pre-chamber geometry, especially for the diameter, number and orientation of the nozzles connecting the main chamber to the pre-chamber, as well as to the definition of the injector nozzles, including sac volume and diameter, number and orientation of the nozzles. Mainly because of the neglected in-flow from the main chamber, these simulations are much less effective than CFD simulations of flow within the pre-chamber plus in-cylinder covering compression and expansion strokes. However, these latter simulations are incontestably more helpful but are undoubtedly also more expensive. The major problems are the different spatial resolutions scales to be used within the injector, the pre-chamber and the main chamber (in the truck engine application discussed later, the displaced volume of a single cylinder is $1800 \mathrm{~cm}^{3}$, the prechamber volume is $1-1.5 \mathrm{~cm}^{3}$, diameters of multi-holes injector nozzles are of the order of $10^{-4} \mathrm{~m}$, lifts of injector needle are of the order of $10^{-5} \mathrm{~m}$ ). Therefore, standalone pre-chamber and pre-chamber plus in-cylinder simulations and CAE engine simulations plus the analogous experiments should all be considered in the development of the DI-JI engine concept.

\section{D ENGINE AND PRE-CHAMBER}

Full cycle engine simulations have then been performed by using GT-POWER [23]. In these computations, the ignition pre-chambers are fitted on the cylinder head of a small high-tech four cylinders, 1.5 litre, highly turbocharged engine having $\mathrm{V}_{\mathrm{D}}=375 \mathrm{~cm}^{3}, \mathrm{~V}_{\mathrm{PC}}=1.5$ $\mathrm{cm}^{3}, \mathrm{CR}=13.8$ and $\mathrm{CR}^{*}=14.5$ better described in [15-20]. In the model previously described in these references, the pre-chamber is now modelled as a volume connected through the main chamber through orifices where fluid can be injected and chemical reactions can occur. All the high pressure and low pressure rails are modelled, as well the HP and LP injectors. These injectors are modelled as volumes connected respectively to the main chamber (HP DI injector) and the pre-chamber (LP DI injector) through orifices, and 
connected to their feeding rail through a passage area prescribed in time. A very basic, one step reaction is considered for combustion within the pre-chamber. Following ignition, all the reactants are replaced by the hot products within a given burning time. This burning time is the one resulting from the previous CFD simulations. In reality, combustion within the pre-chamber is only incomplete, and partially burned products are also injected in the main chamber. These differences are however negligible in the description of flow towards and from the pre-chamber of concern here.

Results are presented in Figure 3 for operation of the engine with $\mathrm{C}_{3} \mathrm{H}_{8}$ propane running $7500 \mathrm{rpm}$ with $\lambda=2.25$ and $\lambda=4.5$. The flow from the sac volume of the HP injector to the main chamber is chocked shortly after injection starts. The flow from the sac volume of the LP injector to the pre-chamber is also chocked shortly after injection starts. Figures $3 \mathrm{a}, 3 \mathrm{~b}$ and $3 \mathrm{c}$ present the pressure drop across the nozzles pre-chamber to main chamber, and the velocity and Mach number through one of the six nozzles connecting the prechamber to the main chamber with $\lambda=2.25$. Figures $3 \mathrm{~d}$, $3 \mathrm{e}$ and $3 \mathrm{f}$ present same results for $\lambda=4.5$. Each nozzle diameter is $1.25 \mathrm{~mm}$, while the flow coefficient is 0.85 for a total effective area of $2 \mathrm{~mm}^{2}$.

During the compression stroke, pressure in the main chamber is larger than the pressure in the pre-chamber, and flow of air and residuals is moving from the main chamber to the pre-chamber. Towards the end of the compression stroke, injection occurs within the main chamber and the pre-chamber. Firing is placed at TDC, when both pre-chamber and main chamber injections end. The addition of hot products in the pre-chamber produces a higher pressure in the pre-chamber than in the main chamber. The flow from the pre-chamber to the main chamber lowers the pressure within the pre-chamber. Combustion finally starts in the main chamber. As soon as the combustion in the main chamber proceeds, pressure in the main chamber becomes again larger than the pressure in the pre-chamber and the flow returns to be from the main chamber to the pre-chamber. The operation of the pre-chamber does not change too much changing the engine load. The engine load is modified by changing the amount of fuel injected in the main chamber and therefore the air-to-fuel ratio.

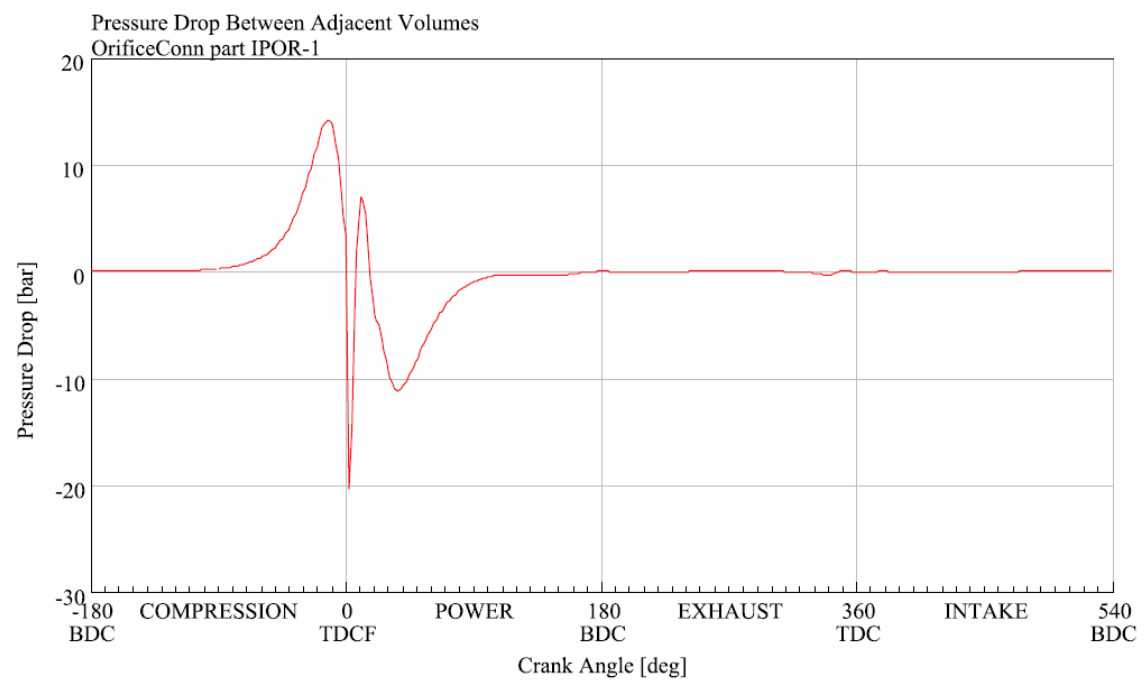

Figure $3 \mathrm{a}$-Computed pressure drop across pre-chamber to main chamber nozzles (propane, $\lambda=2.25,7,500 \mathrm{Rpm}$ ).

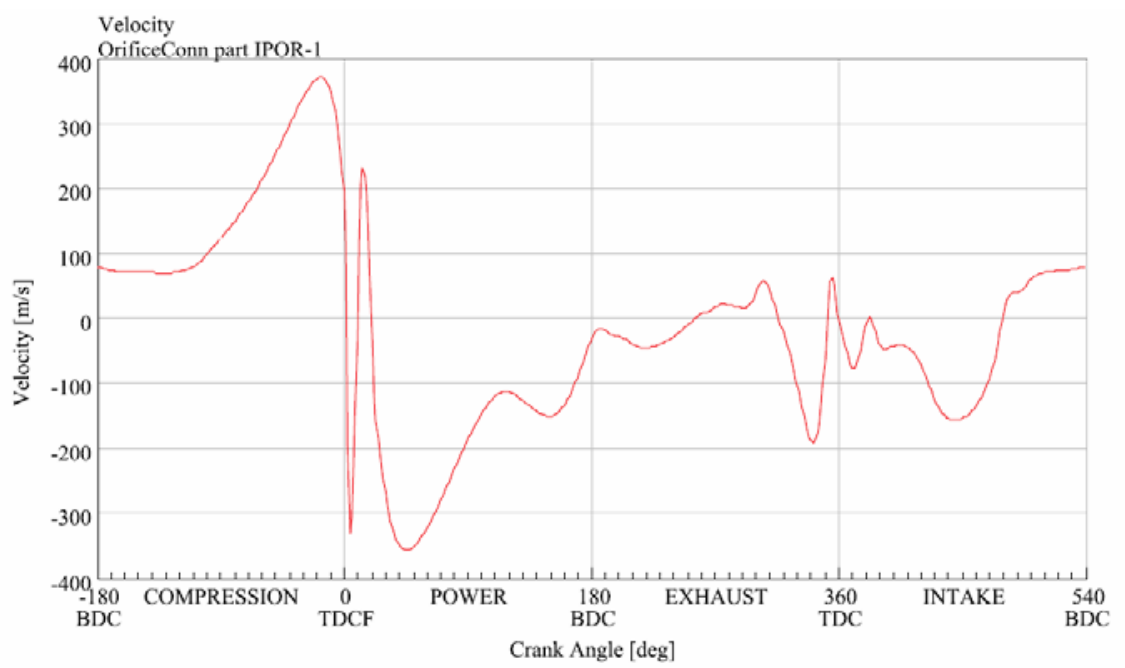

Figure $3 b$ - Computed velocity through the pre-chamber to main chamber nozzles (propane, $\lambda=2.25,7,500 \mathrm{Rpm}$ ). 


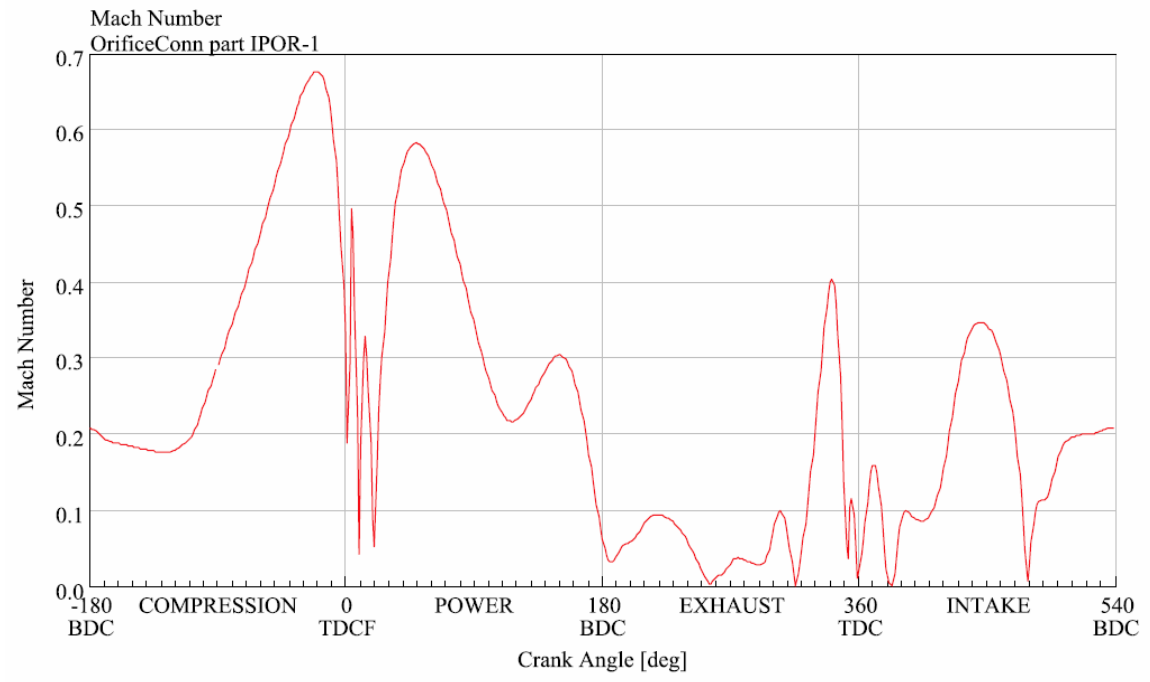

Figure $3 c$-Computed Mach number through the pre-chamber to main chamber nozzles (propane, $\lambda=2.25,7,500 \mathrm{Rpm}$ ).

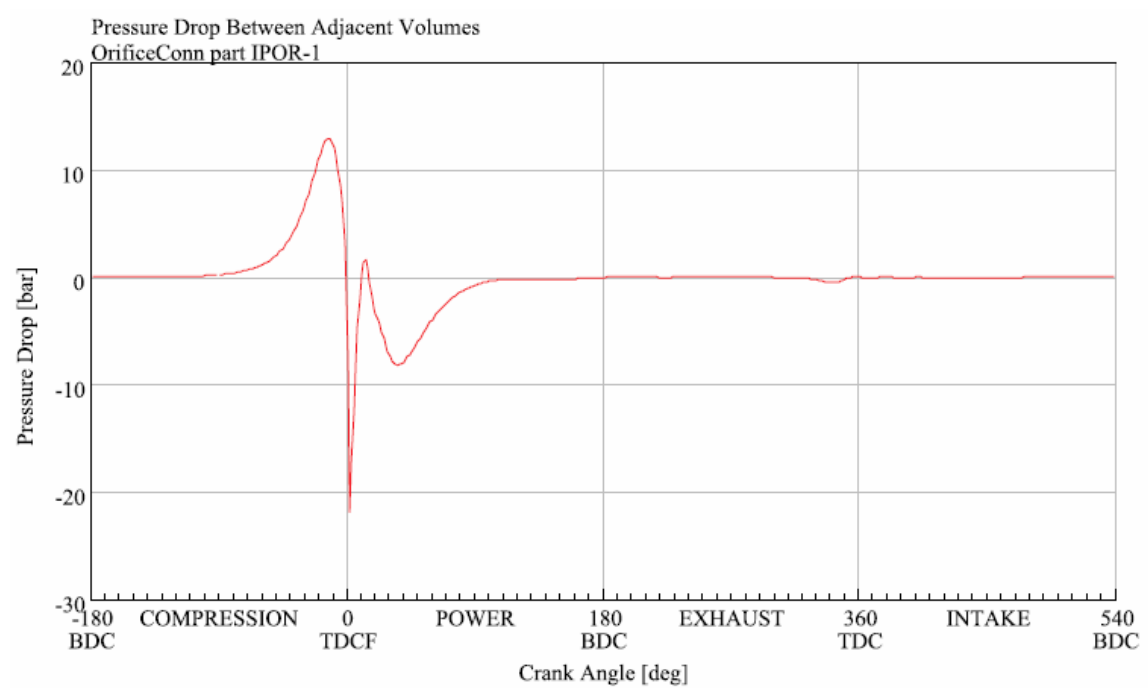

Figure $3 \mathrm{~d}$-Computed pressure drop across pre-chamber to main chamber nozzles (propane, $\lambda=4.5,7,500 \mathrm{Rpm}$ ).

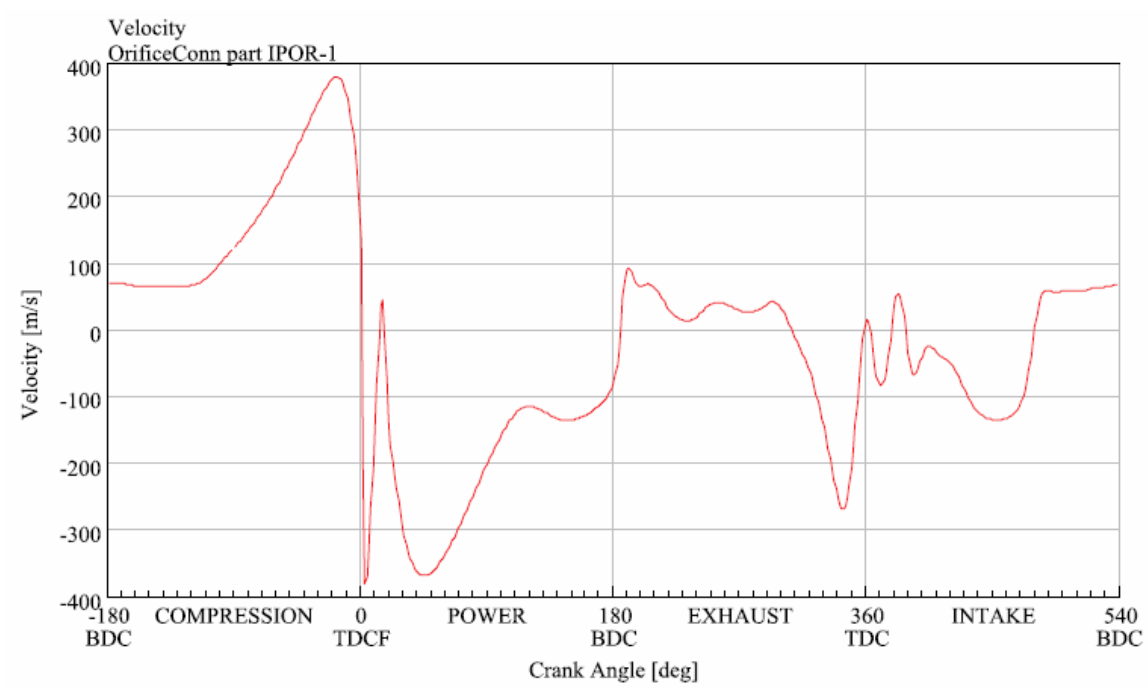

Figure $3 \mathrm{e}-$ Computed velocity through the pre-chamber to main chamber nozzles (propane, $\lambda=4.5,7,500 \mathrm{Rpm}$ ). 


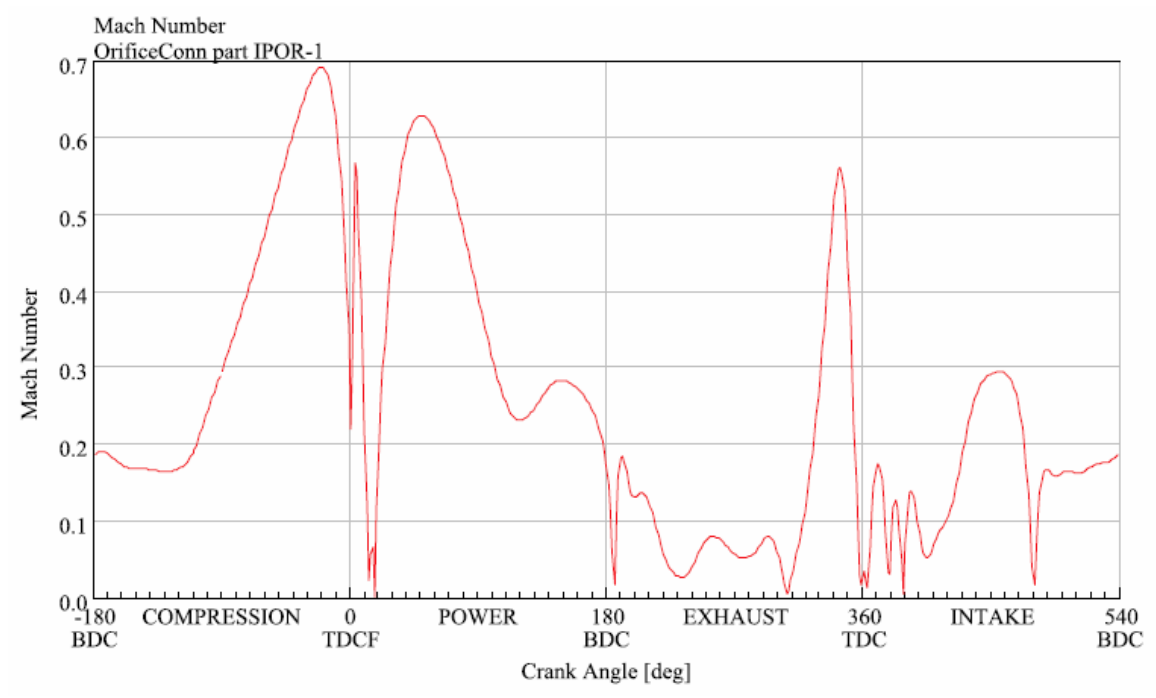

Figure $3 \mathrm{f}$-Computed Mach number through the pre-chamber to main chamber nozzles (propane, $\lambda=4.5,7,500 \mathrm{Rpm}$ )

Combustion duration $\Delta \theta_{10-90 \%}$ is assumed to be about 10 degrees crank angle with propane. During the power stoke, the effect of the increased volume due to the piston motion quickly exceeds the effect of the heat release. Then the main chamber pressure falls below the pre-chamber pressure and the flow is again from the pre-chamber to the main chamber up to the end of the power stroke.

The quantity of unburned fuel trapped within the pre-chamber is negligible. These results clearly show the relevance of the neglected flow from and to the main chamber that will certainly deserve better consideration if the jet ignition pre-chamber has to be optimized.

Results show very interesting BSFC and brake efficiency. In the range of engine speed 3500-7500 rpm, BSFC at WOT and MBT or knock limited spark timing has a minimum of $165 \mathrm{~g} / \mathrm{kW} / \mathrm{h}$ with propane and less than $65 \mathrm{~g} / \mathrm{kW} / \mathrm{h}$ with hydrogen about $3500 \mathrm{Rpm}$. This corresponds to brake efficiencies of almost $48 \%$. These results clearly show the potentials to achieve even better brake efficiencies exceeding the $50 \%$ mark in engines redesigned for lower speeds, where friction losses are lower and air-to-fuel equivalence ratios may be even leaner.

\section{D PRE-CHAMBER AND ENGINE CYLINDER}

STAR-CCM [22] injection and combustion simulations have been performed for a single engine cylinder of a larger 3.6 litres, naturally aspirated six cylinders, gasoline engine fuelled with hydrogen. This engine has $V_{D}=600 \mathrm{~cm}^{3}, V_{P C}=1.5 \mathrm{~cm}^{3}, C R=10.8$ and $\mathrm{CR}^{*}=11.0$. Computations start at intake valve closure when initial conditions are set by using results of CAE simulations, and end at exhaust valve opening. Figure 4a presents a sectional view of computational domain made up of the in-cylinder and pre-chamber volumes (piston is at TDC position). Piston moves following the compression and expansion strokes, and the computational domain made up of the in-cylinder volume contract or expands accordingly. The computational grid, made up of 300,000 polyhedral cells to keep the computational time and the internal memory requirements below 1,600,000 K memory usage. Morphing is used to change the grid density to the variable in cylinder space aiming to produce computationally effective mesh elements in size and shape. Main chamber and pre-chamber injections are performed with very basic single holes injectors where sonic velocity is set during injector opening times. The spark discharge is simulated as a pulse temperature igniter, i.e. a small sphere in between the electrodes where the temperature is risen up to $2500 \mathrm{~K}$ during a prescribed time. Simulations have been performed neglecting the residual gases within the cylinder and the pre-chamber at intake valve closure.

The flow is considered turbulent, compressible, reacting, multi species. Turbulence is modelled by using a Reynolds-Averaged Navier-Stokes (RANS) turbulence model; in particular 2 equations K- $\varepsilon$ model with a two layer all y+ wall treatment [22]. Other modelling of turbulence is available, including large eddy simulation (LES) and detached eddy simulation (DES), and within the RANS family the Spalart-Allmaras, K- $\Omega$ or Reynolds Stress Transport variants, but the K- $\varepsilon$ RANS is preferred for simplicity, generality and reliability. Kinetics equations are obtained by using DARS-CFD [33]. Hydrogen combustion in air is represented using a complex chemistry model of 9 species and 19 reversible reactions as detailed below:

1. $\mathrm{H}_{2}+\mathrm{O}_{2}=2 \cdot \mathrm{OH}$

2. $\mathrm{H}_{2}+\mathrm{OH}=\mathrm{H}_{2} \mathrm{O}+\mathrm{H}$

3. $\mathrm{H}+\mathrm{O}_{2}=\mathrm{OH}+\mathrm{O}$

4. $\mathrm{O}+\mathrm{H}_{2}=\mathrm{OH}+\mathrm{H}$

5. $\mathrm{H}+\mathrm{O}_{2}+\mathrm{M}_{1}=\mathrm{HO}_{2}+\mathrm{M}_{1}$ 

6. $\mathrm{H}+2 \cdot \mathrm{O}_{2}=\mathrm{HO}_{2}+\mathrm{O}_{2}$
7. $\mathrm{H}+\mathrm{O}_{2}+\mathrm{N}_{2}=\mathrm{HO}_{2}+\mathrm{N}_{2}$
8. $\mathrm{OH}+\mathrm{HO}_{2}=\mathrm{H}_{2} \mathrm{O}+\mathrm{O}_{2}$
9. $\mathrm{H}+\mathrm{HO}_{2}=2 \cdot \mathrm{OH}$
10. $\mathrm{O}+\mathrm{HO}_{2}=\mathrm{O}_{2}+\mathrm{OH}$
11. $2 \cdot \mathrm{OH}=\mathrm{O}+\mathrm{H}_{2} \mathrm{O}$
12. $\mathrm{H}_{2}+\mathrm{M}_{2}=2 \cdot \mathrm{H}+\mathrm{M}_{2}$
13. $\mathrm{O}_{2}+\mathrm{M}=2 \cdot \mathrm{O}+\mathrm{M}$
14. $\mathrm{H}+\mathrm{OH}+\mathrm{M}_{3}=\mathrm{H}_{2} \mathrm{O}+\mathrm{M}_{3}$
15. $\mathrm{H}+\mathrm{HO}_{2}=\mathrm{H}_{2}+\mathrm{O}_{2}$
16. $2 \cdot \mathrm{HO}_{2}=\mathrm{H}_{2} \mathrm{O}_{2}+\mathrm{O}_{2}$
17. $\mathrm{H}_{2} \mathrm{O}_{2}+\mathrm{M}=2 \cdot \mathrm{OH}+\mathrm{M}$
18. $\mathrm{H}_{2} \mathrm{O}_{2}+\mathrm{H}=\mathrm{HO}_{2}+\mathrm{H}_{2}$
19. $\mathrm{H}_{2} \mathrm{O}_{2}+\mathrm{OH}=\mathrm{H}_{2} \mathrm{O}+\mathrm{HO}_{2}$

The kinetics equations are expressed through Arrhenius rate constants $\mathrm{A}, \mathrm{n}$ and $\mathrm{E}_{\mathrm{a}}$ :

$k=A \cdot T^{n} \cdot e^{-E_{a} / R \cdot T}$

Values of these constants are proposed in [36]. Transport and diffusion equations are solved for the nine chemical species, namely for $\mathrm{H}_{2}, \mathrm{H}, \mathrm{O}_{2}, \mathrm{~N}_{2}, \mathrm{HO}_{2}, \mathrm{OH}, \mathrm{HO}_{2}, \mathrm{H}_{2} \mathrm{O}_{2}$ and O. STAR-CCM solves the Partial Differential Equations (PDE) for energy and species conservation [22]:

$$
\begin{aligned}
& \frac{\partial}{\partial t} \rho Y_{k}+\frac{\partial}{\partial x_{j}}\left(\rho \cdot u_{j} \cdot Y_{k}+F_{k, j}\right)=0 \\
& \frac{\partial}{\partial t} \rho h+\frac{\partial}{\partial x_{j}}\left(\rho \cdot u_{j} \cdot h+F_{h, j}\right)= \\
& =\frac{\partial}{\partial t} p+u_{j} \cdot \frac{\partial}{\partial x_{j}} p+\tau_{i, j} \cdot \frac{\partial}{\partial x_{j}} u_{i}
\end{aligned}
$$

While DARS-CFD solves the Ordinary Differential Equations (ODE) for chemical kinetics [33]:

$$
\frac{\partial}{\partial t} Y_{i}=\frac{\omega_{i} \cdot W_{i}}{\rho}
$$

When chemical kinetics is the limiting factor of the reacting system under investigation, near-perfect mixing of reactants and products is usually accomplished. However, normally these mixing mechanisms have to rely on fluid motion or large-scale eddies and turbulence to provide the mixing. Local turbulence is particularly important as it promotes micro-scale mixing among the gas species. If the turbulence is too weak to provide fast mixing among the gas species, the micro-mixing process will interfere with the chemical kinetics.

Turbulence intensity is supposed to affect combustion scaling reaction rates following the Kong-Reitz model [32]:

$$
s_{i}^{t}=s_{i}^{l} \frac{\tau_{k i n}}{\tau_{k i n}+f \cdot \tau_{\text {turb }}}
$$

Where

$$
\tau_{\text {turb }}=C \cdot \frac{K}{\varepsilon}
$$

And

$f=\frac{1-\exp (-r)}{0.632}$

$r=\frac{m_{\mathrm{H}_{2} \mathrm{O}}+m_{\mathrm{H}_{2}}}{1-m_{N_{2}}}$ 
Figures $4 \mathrm{~b}$ to 41 present the computed temperature and velocity fields within the in-cylinder space at different crank angle positions about firing top dead centre, from $20^{\circ}$ crank angle before top dead centre to $30^{\circ}$ crank angle after top dead centre. The engine speed is $7500 \mathrm{Rpm}$, while the air-to-fuel equivalent ratio of the hydrogen fuelled engine is $\lambda=2.25$. The load is reduced reducing the amount of fuel injected within the main chamber therefore increasing the air-to-fuel equivalent ratio. The air-to-fuel equivalent ratio within the pre-chamber is fixed to conditions slightly rich of stoichiometry $\lambda=1-0.95$. The spark is advanced with reference to top dead centre position to allow combustion initiation.

Kinetics is important in the early phase of combustion. Ignition of the pre-chamber mixtures takes a finite time despite of the almost stoichiometric conditions. As soon as combustion within the pre-chamber is fully initiated the jet of partially combusted, hot products quickly spread combustion all over the main chamber. Combustion then completes within a short time despite the lean composition.

Simulations with hydrogen have also been performed for the glow plug jet ignition pre-chamber [36, 37]. The spark plug pre-chamber is preferred for the large truck engine application because of its more advanced development to prototypes and because the small prechamber to main chamber volume ratio reduces the advantages of the glow plug pre-chamber.

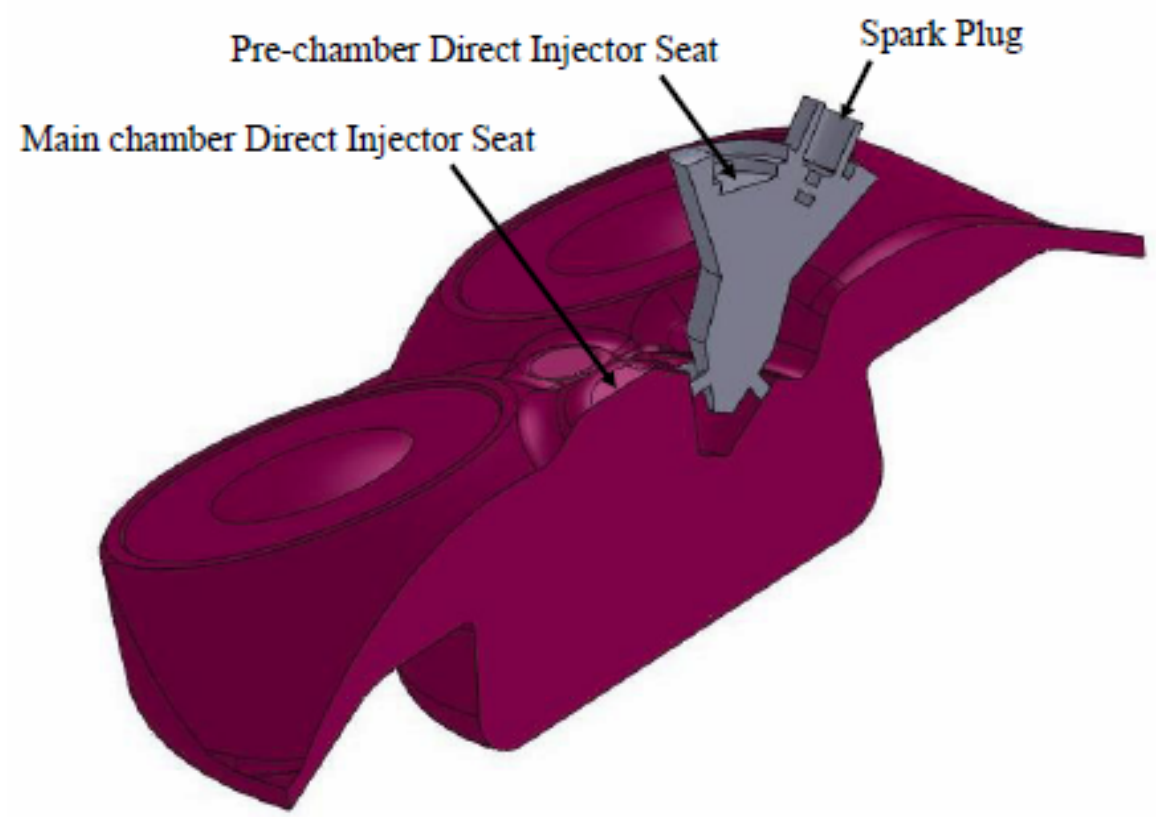

Figure $4 \mathrm{a}$ - Sectional view of computational domain made up of the in-cylinder and pre-chamber volumes (piston is at TDC position).

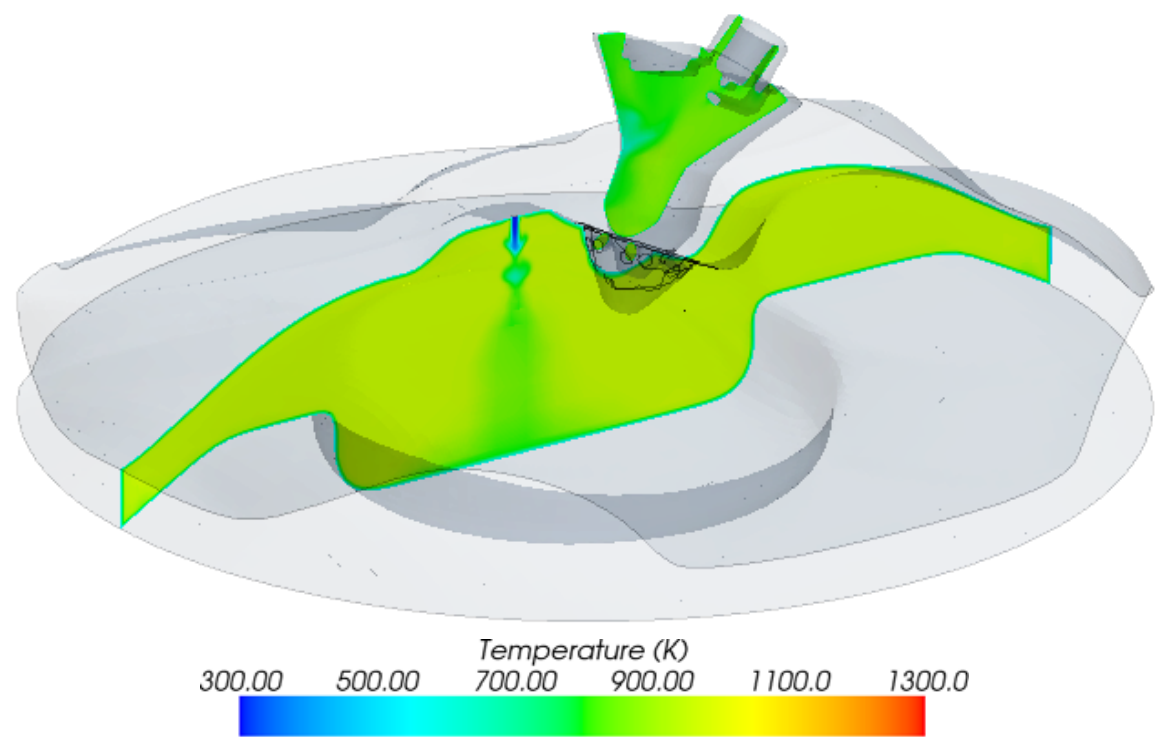

Figure $4 b-$ Computed temperature field within the cylinder $20^{\circ}$ crank angle before TDC (hydrogen, $\lambda=2.25,7,500 \mathrm{Rpm}$ ). 


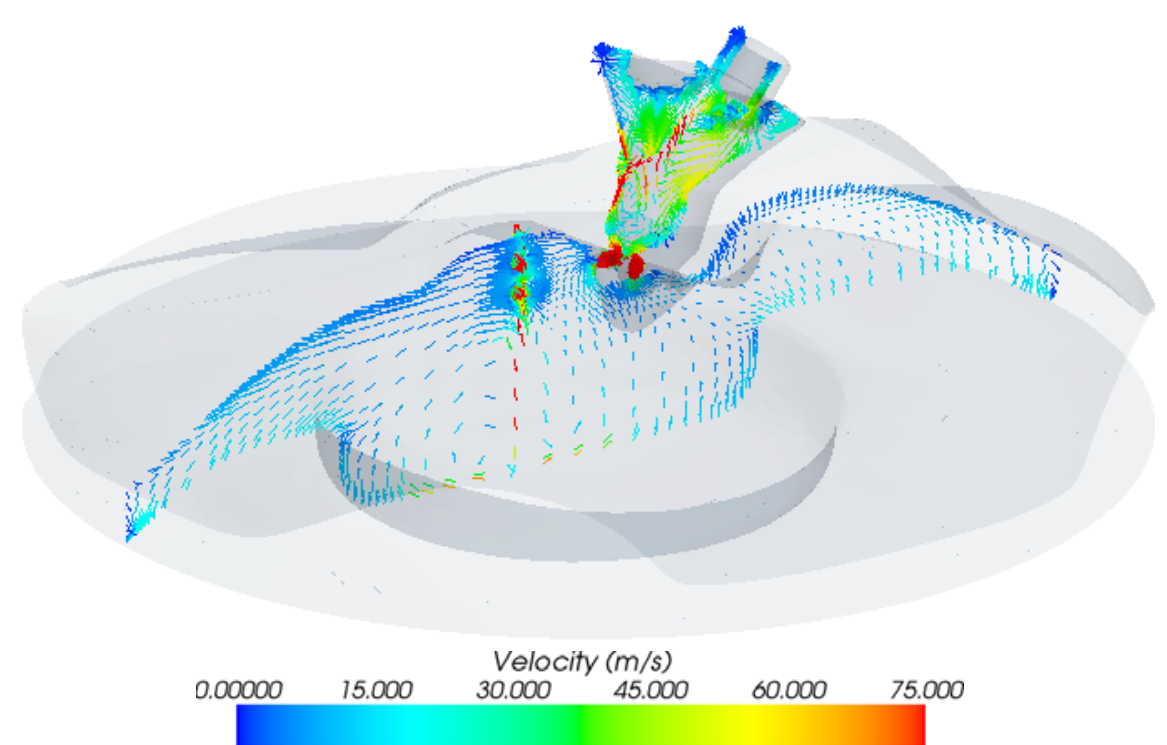

Figure $4 \mathrm{c}-$ Computed velocity field within the cylinder $20^{\circ}$ crank angle before TDC (hydrogen, $\lambda=2.25,7,500 \mathrm{Rpm}$ ).

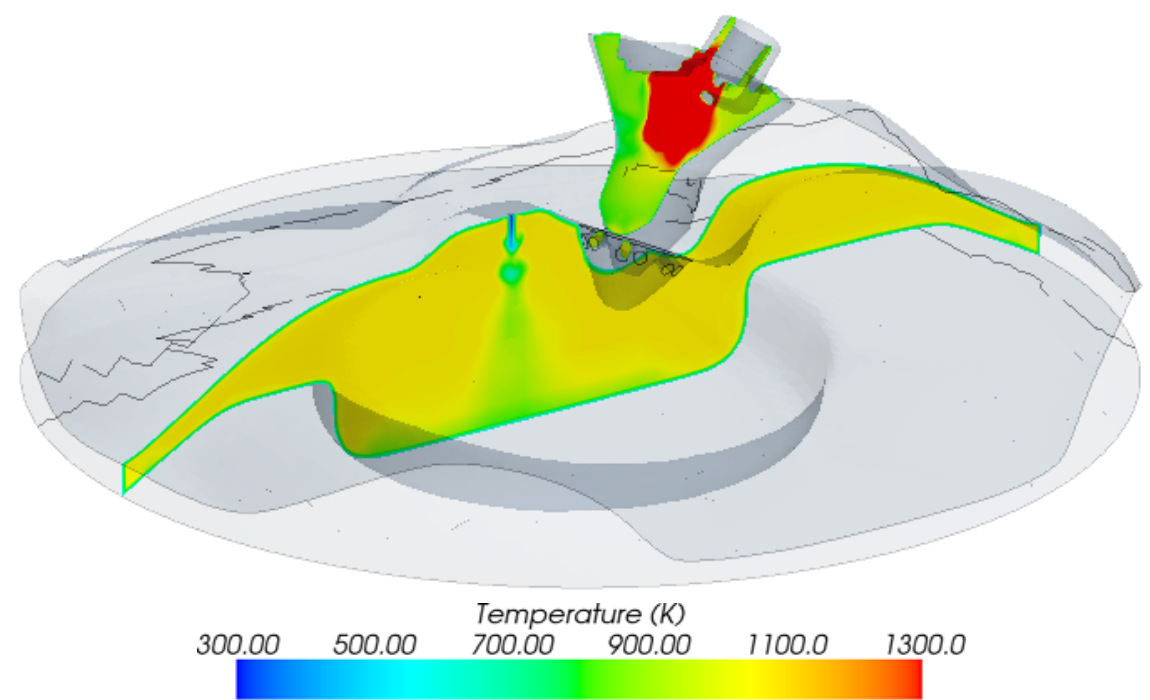

Figure $4 \mathrm{~d}$ - Computed temperature field within the cylinder $10^{\circ}$ crank angle before TDC (hydrogen, $\lambda=2.25,7,500 \mathrm{Rpm}$ ).

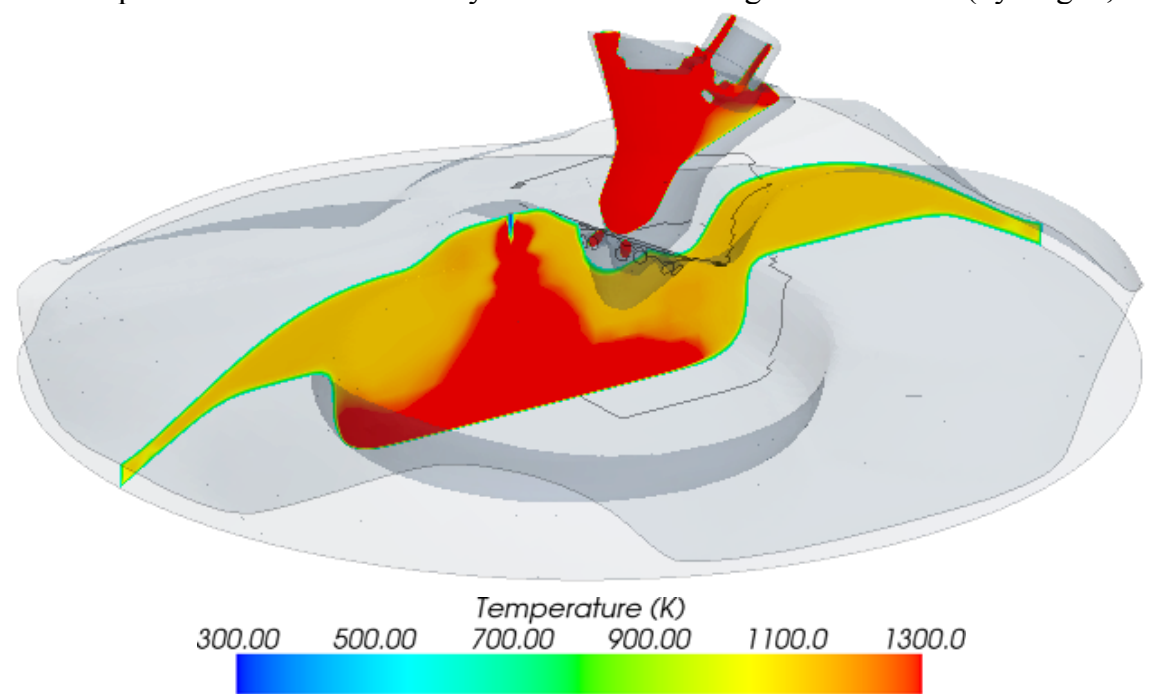

Figure $4 \mathrm{e}-$ Computed temperature field within the cylinder at TDC (hydrogen, $\lambda=2.25,7,500 \mathrm{Rpm}$ ). 


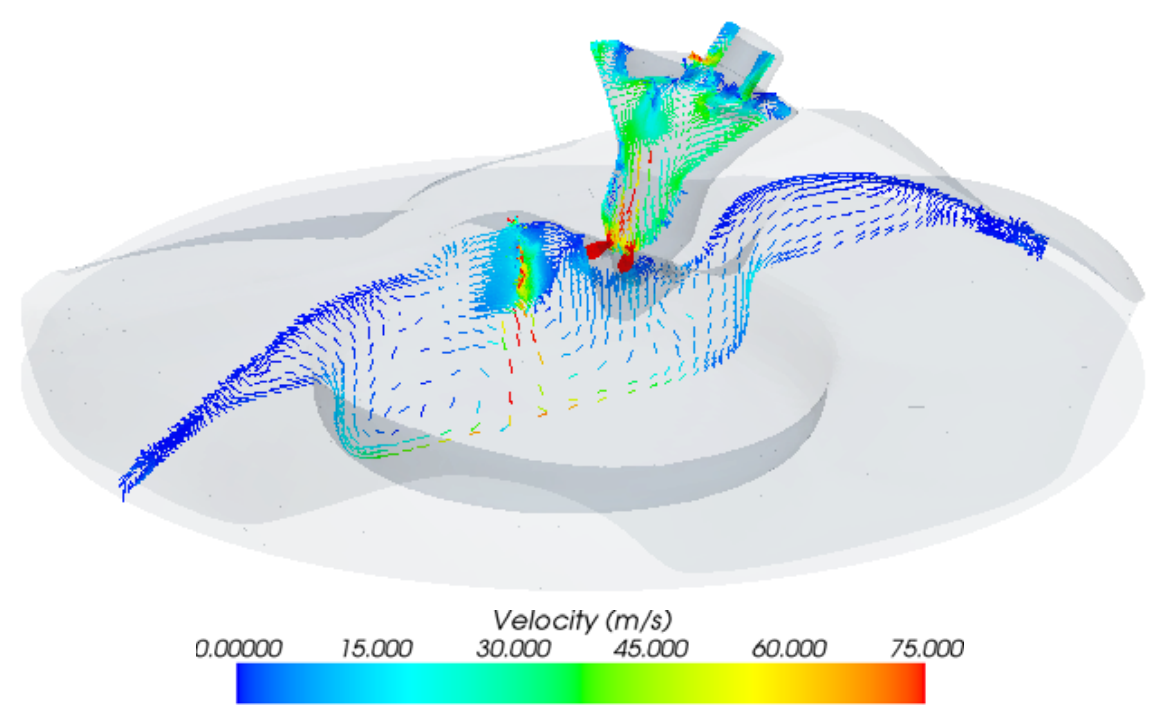

Figure $4 \mathrm{f}-$ Computed velocity field within the cylinder at TDC (hydrogen, $\lambda=2.25,7,500 \mathrm{Rpm}$ ).

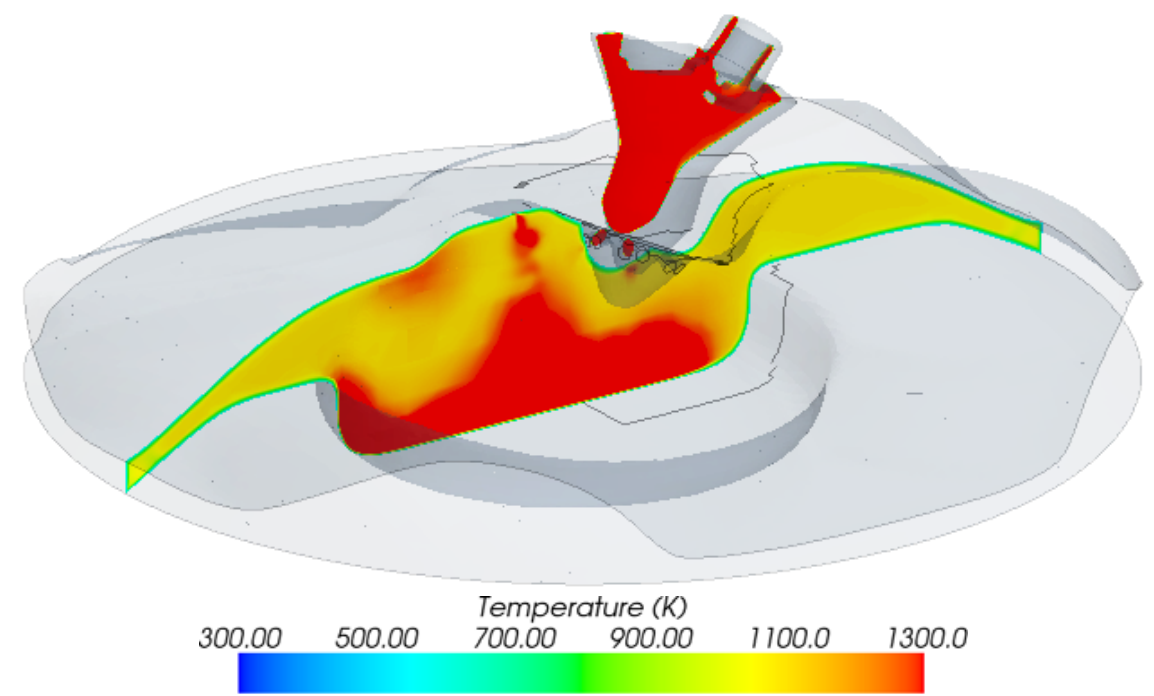

Figure $4 \mathrm{~g}$ - Computed temperature field within the cylinder $10^{\circ}$ crank angle after TDC (hydrogen, $\lambda=2.25,7,500 \mathrm{Rpm}$ ).

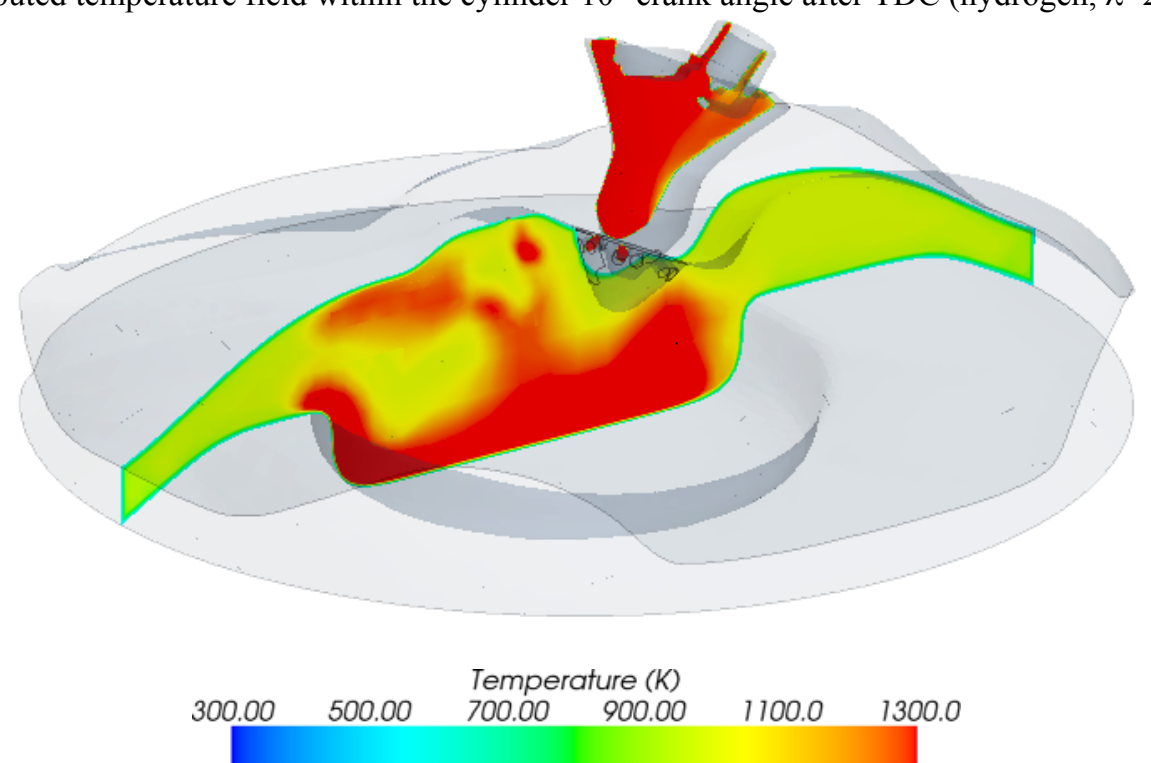

Figure $4 \mathrm{~h}$ - Computed temperature field within the cylinder $20^{\circ}$ crank angle after TDC (hydrogen, $\lambda=2.25,7,500 \mathrm{Rpm}$ ). 


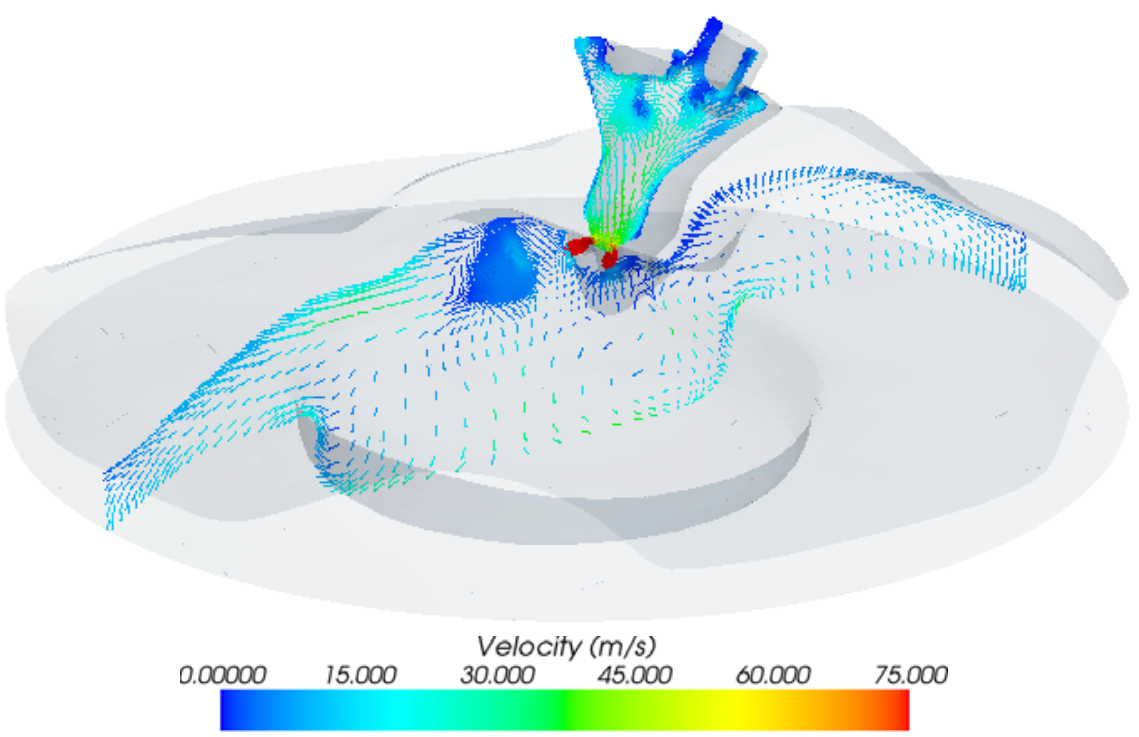

Figure $4 \mathrm{i}-$ Computed velocity field within the cylinder $20^{\circ}$ crank angle after TDC (hydrogen, $\lambda=2.25,7,500 \mathrm{Rpm}$ ).

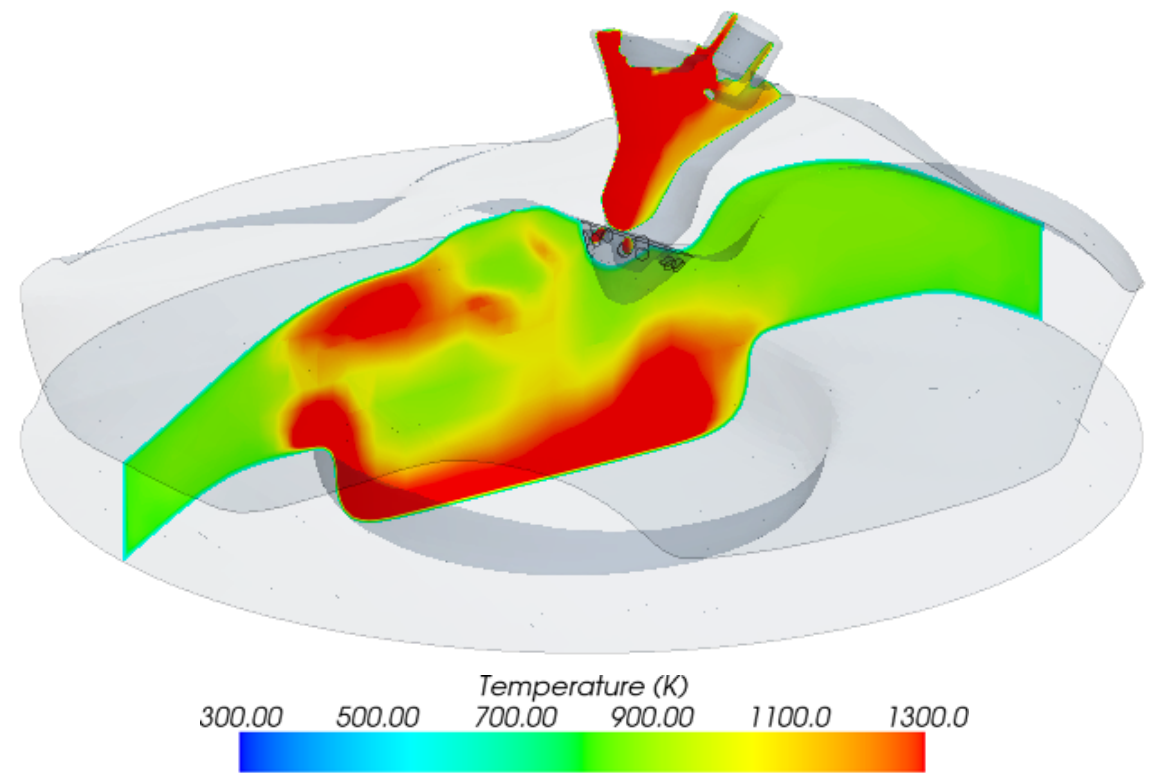

Figure 41 - Computed temperature field within the cylinder $30^{\circ}$ crank angle after TDC (hydrogen, $\lambda=2.25,7,500 \mathrm{Rpm}$ ).

Previous results are in line with what was previously measured in the only experimental activity performed so far coupling direct injection with a small size jet ignition device. Experimental results have been previously obtained on a single cylinder, optical access test engine in [28]. The engine was naturally aspirated, with a four-valve cylinder head and a pent-roof combustion chamber and accommodates a central Hydrogen Assisted Jet Ignition (HAJI) pre-chamber, plus one side direct injector and one port injector to simulate either Direct Injection (DI) and Port Fuel Injection (PFI) operation, and a pressure sensor for combustion data analysis

The engine had a large bore to stroke ratio, having a bore of $89 \mathrm{~mm}$ and a stroke of just $66 \mathrm{~mm}$, and a compression ratio of 10.3:1 and was not cooled. Early and late direct injections were considered for lean stratified operation. The jet ignition device had 6 holes of diameter $\Phi=1.25 \mathrm{~mm}$, a volume of $1.3 \mathrm{~cm} 3$, and was accommodating a fuel injector for hydrogen and a small spark plug $\Phi=8 \mathrm{~mm}$ diameter. The mixture preparation was not optimal, due to the side location of the injector and the poor atomization properties of the injector, as well as the low temperatures of the in-cylinder walls and in-cylinder charge. Experiments were carried out with butane as the main chamber fuel and hydrogen as the jet ignition pre-chamber fuel. For an amount of hydrogen injected in the jet ignition prechamber of about $2 \mathrm{mg} / \mathrm{s}$ (roughly $5 \%$ of the total fuel energy), an amount of butane injected of $0.11 \mathrm{~g} / \mathrm{s}$ on the engine running 1,500 rpm with $\lambda$ controlled by throttling the intake. Combustion duration $\Delta \theta 5-95 \%$ were $17-19^{\circ}$ crank angle with $\lambda=1.2-1.4$ and early DI, and $17-20^{\circ}$ crank angle with $\lambda=1.6-2.0$ and late DI [28]. 


\section{SIMULATIONS OF HDT ENGINE PERFORMANCE}

WAVE simulations [31] have been performed for a production 11 litre, in-line six, 24 valve Diesel Truck engine modified to fit a jet ignition pre-chamber and run propane fuel. The basic engine data are presented in Table 1. WAVE and GT-POWER are very similar codes having in common the theoretical background, and mainly differing in supported applications, user interface and distribution policy. The baseline Diesel truck engine is turbo charged, with inter cooler and cooled Exhaust Gas Recirculation (EGR), full load boost of 1.5 to 2.6 , and operates full load with $\lambda=1.55$. The LPG version is obtained by replacing the Diesel fuel injector with a direct injector for the LPG fuel plus a small jet ignition device and reducing the compression ratio to $\mathrm{CR}=12$. Operation with $\lambda=1.55$ provides similar performances to the Diesel engine and it is considered first. Brake thermal efficiency, mean effective pressure and specific $\mathrm{CO}_{2}$ production are presented in Figure 5 for the Diesel and LPG versions.

\begin{tabular}{||c|c||}
\hline Number of Cylinders & 6 \\
\hline Configuration & In-line \\
\hline Turbo charger & Fixed geometry \\
\hline Bore [mm] & 123 \\
\hline Stroke [mm] & 152 \\
\hline Connecting rod length [mm] & 255 \\
\hline Compression ratio & 16 \\
\hline Swept Volume [1] & 11 \\
\hline
\end{tabular}

Table 1 - Basic engine data.

Heat transfer is modelled by using the original Woschni model [31], where the charge is supposed to have a uniform heat flow coefficient and velocity on all surfaces of the cylinder. The model is applied with multipliers to account for intake valves open or closed 1 or 0.9 respectively, and piston top and cylinder head surface multipliers 1.09 and 1 respectively, all over the range of speeds and loads. Averaged surface temperatures for piston top, cylinder head, intake and exhaust valves are assumed to change with speed only from 623 to $573 \mathrm{~K}$, while the liner temperature is assumed to change with speed from 473 to $423 \mathrm{~K}$. These temperatures are kept constant when changing the load. A more detailed and accurate modelling of the heat transfer processes is considered not essential at this stage.

Average $\mathrm{CO}_{2}$ emissions from the hydrocarbon fuels are computed considering an oxidation factor to be applied to the carbon content to account for a small portion of the fuel that is not oxidized into $\mathrm{CO}_{2}$. The Intergovernmental Panel on Climate Change (IPCC) guidelines for calculating emissions inventories require that an oxidation factor be applied to the carbon content to account for a small portion of the fuel that is not oxidized into $\mathrm{CO}_{2}$. For all oil and oil products, the oxidation factor used is 0.99 ( 99 percent of the carbon in the fuel is eventually oxidized, while 1 percent remains un-oxidized). Finally, to calculate the $\mathrm{CO}_{2}$ emissions from a $\mathrm{kg}$ of fuel, the carbon emissions are first obtained from the ratio of the molecular weight of carbon to the molecular weight of the hydrocarbon fuel, and then the carbon emissions are multiplied by the ratio of the molecular weight of $\mathrm{CO}_{2}$ to the molecular weight of carbon. Diesel fuel is considered a hydrocarbon fuel having $\mathrm{C}_{15} \mathrm{H}_{25.05}$ and $\mathrm{LHV}=4.28 \cdot 10^{7} \mathrm{~J} / \mathrm{Kg}$. LPG fuel is considered propane $\mathrm{C}_{3} \mathrm{H}_{8}$ and $\mathrm{LHV}=4.655 \cdot 10^{7} \mathrm{~J} / \mathrm{Kg}$. $\mathrm{kg}$ of $\mathrm{CO}_{2}$ per $\mathrm{kg}$ of $\mathrm{C}_{\mathrm{n}} \mathrm{H}_{\mathrm{m}}$ fuel is 3.19 for Diesel, 3.13 for gasoline, 2.97 for propane and 2.72 for methane.

The LPG converted engine has about same performance of the Diesel engine running about same air-to-fuel equivalence ratio (i.e. same BMEP vs. engine speed full load). This feature makes the conversion extremely attractive, because the most part of the vehicle management system may remain unaltered. The LPG converted engine has clear advantages in terms of $\mathrm{CO}_{2}$ production, showing an almost $20 \%$ reduction, and an increased efficiency of up to $2 \%$ at higher speeds because the spark plug initiated jet ignition combustion is less sensitive to engine speed than the diffusion combustion. The major advantage of LPG is however the negligible particulate production due to the partially premixed gaseous combustion replacing the liquid diffusion combustion of Diesel, possibly requiring no after treatment to meet Euro 6 emission standards if the ultra lean operation would allow negligible $\mathrm{NOx}^{-2 m i s s i o n s . ~} \mathrm{NO}_{\mathrm{x}}$ formation within the LPG engine is expected to require after treatment to meet Euro 6 emission standards running these air-to-fuel equivalence ratios.

The part load operation is achieved by changing the quantity of fuel injected in the main chamber Diesel-like. However, the direct injection jet ignition engine concept uses premixed rather than diffusion combustion. The main injector has to create a region of lean, ignitable mixtures of fuel and air behind the jet ignition nozzles. Brake efficiency and mean effective pressure results for the LPG engine with variable air-to-fuel equivalence ratio are presented in Figures 6a and 6b. The direct injection jet ignition LPG engine has an almost constant brake efficiency exceeding $40 \%$ from one third to full load. Use of air-to-fuel equivalence ratios smaller than $\lambda=2.25$ could in principle allow meeting Euro 6 emission standards for $\mathrm{NO}_{\mathrm{x}}$ without after treatment. However, at the expenses of low brake mean effective pressure outputs. Figure 7 finally presents the brake specific fuel consumption and brake efficiency maps computed for the LPG fuelled truck engine. The engine is operating over the most part of the map with efficiencies well over $42 \%$ and brake specific fuel consumption of less than $180 \mathrm{~g} / \mathrm{kWh}$ of LPG fuel. 


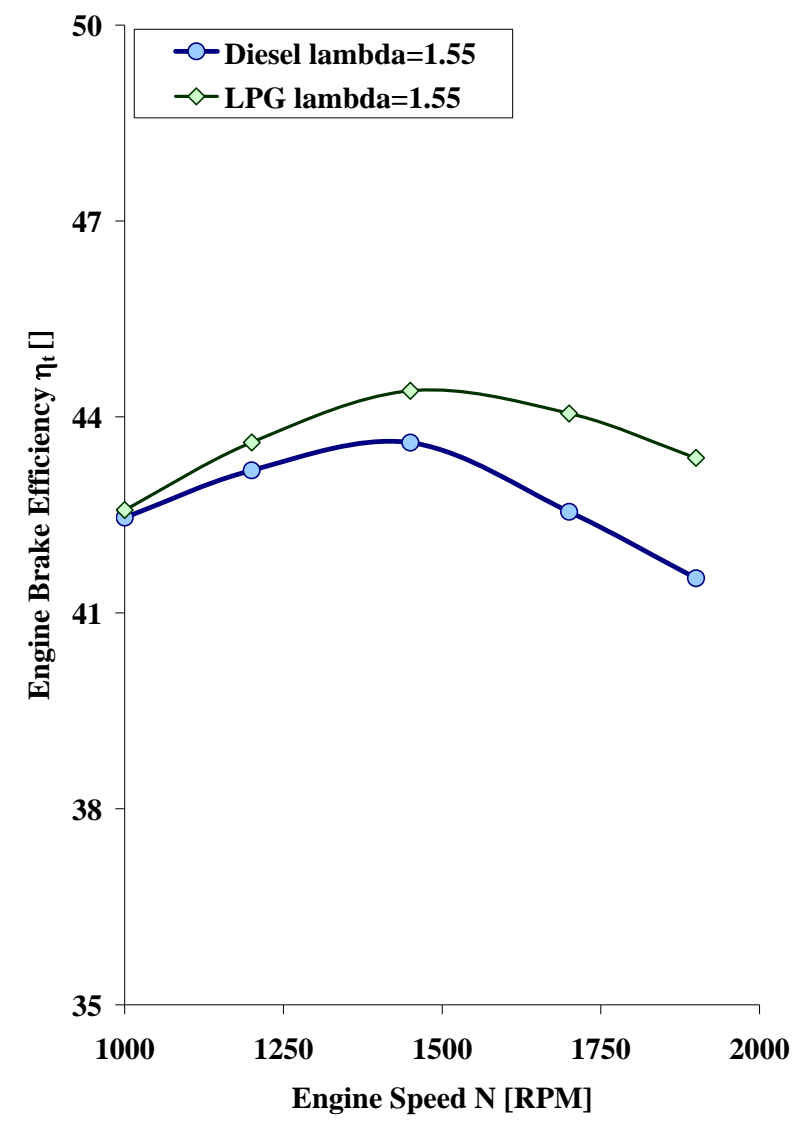

Figure 5a-Computed brake efficiency for the Diesel and LPG fuelled truck engine $\lambda=1.55$.

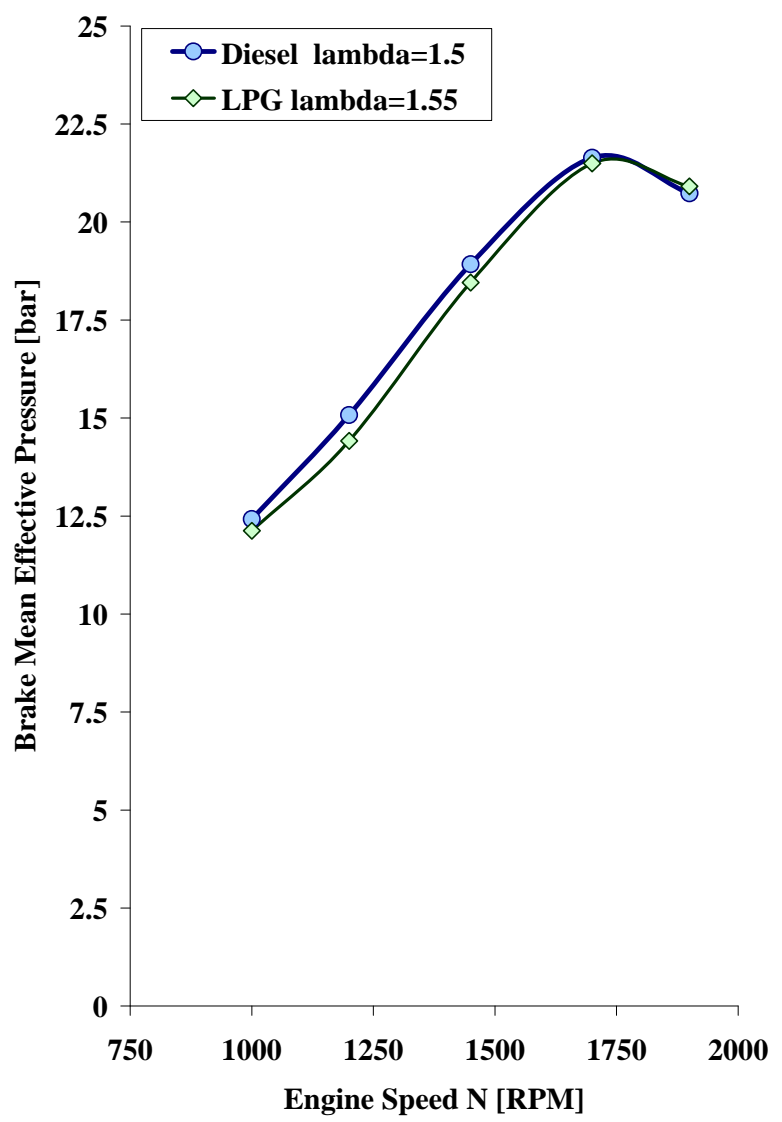

Figure $5 b$ - Computed brake mean effective pressure for the Diesel and LPG fuelled truck engine $\lambda=1.55$. 


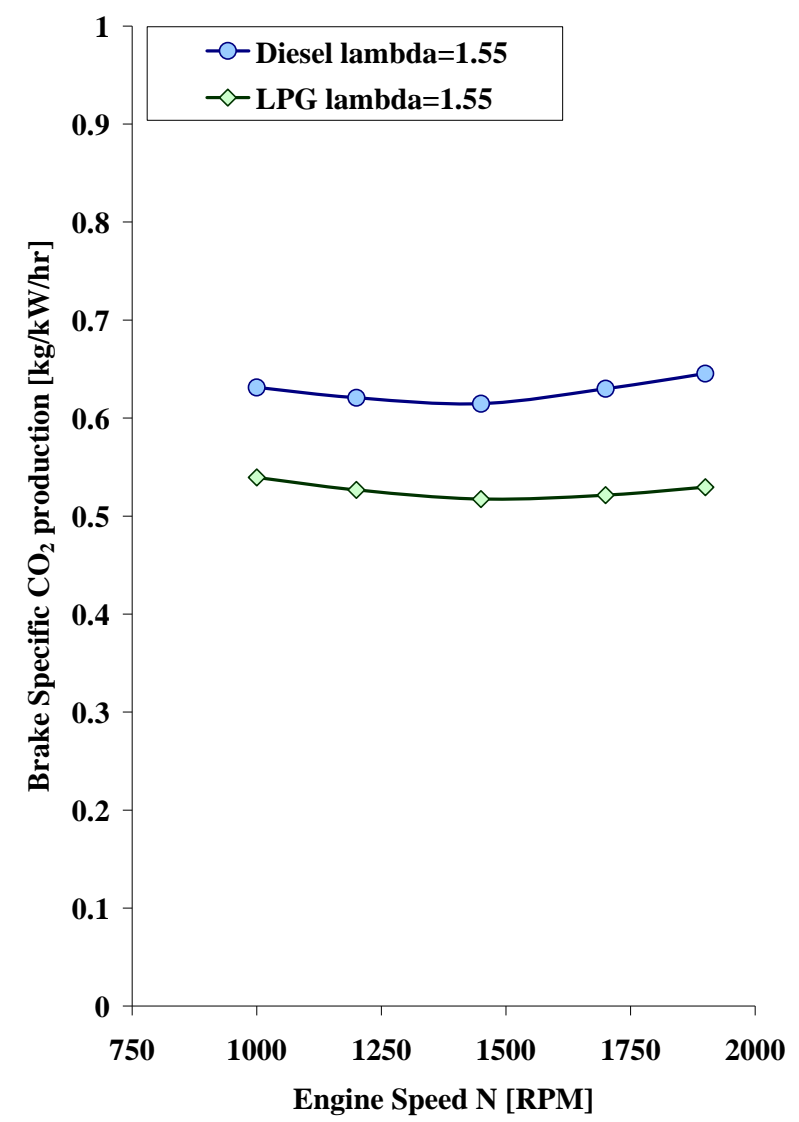

Figure $5 \mathrm{c}-$ Computed brake specific $\mathrm{CO}_{2}$ production for the Diesel and LPG fuelled truck engine $\lambda=1.55$.

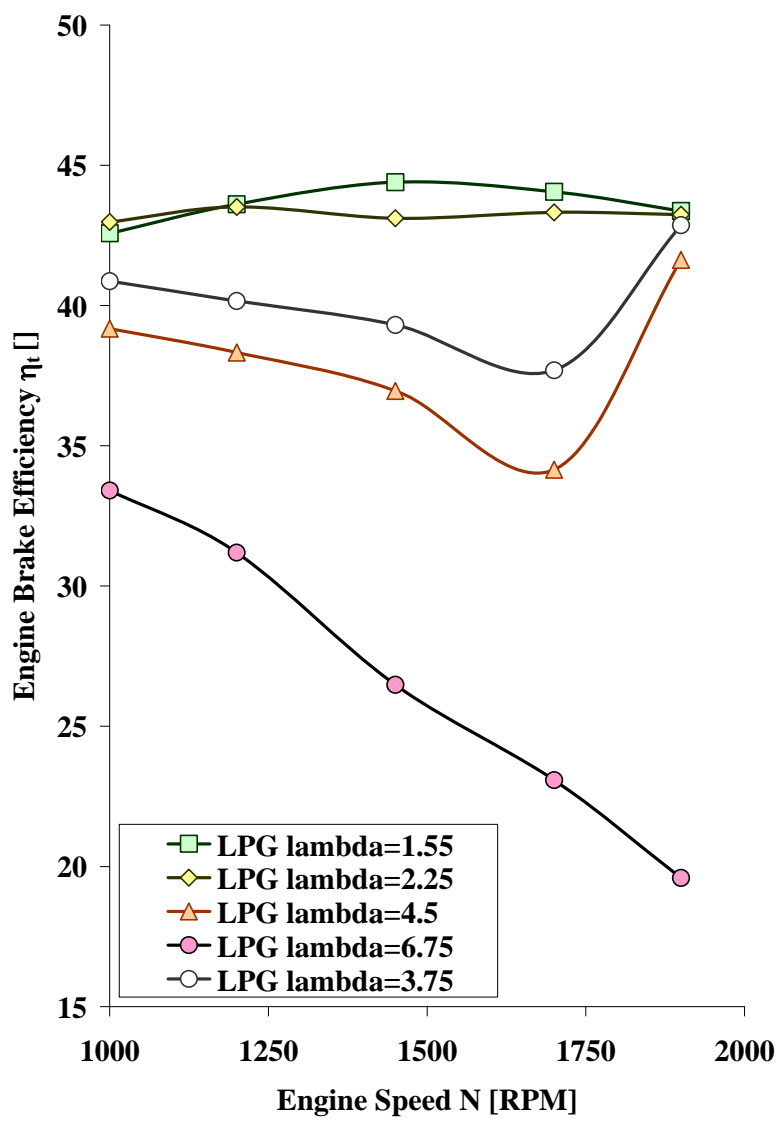

Figure $6 \mathrm{a}$ - Computed brake efficiency for the LPG fuelled truck engine with variable $\lambda 1.55$ to 6.75 . 


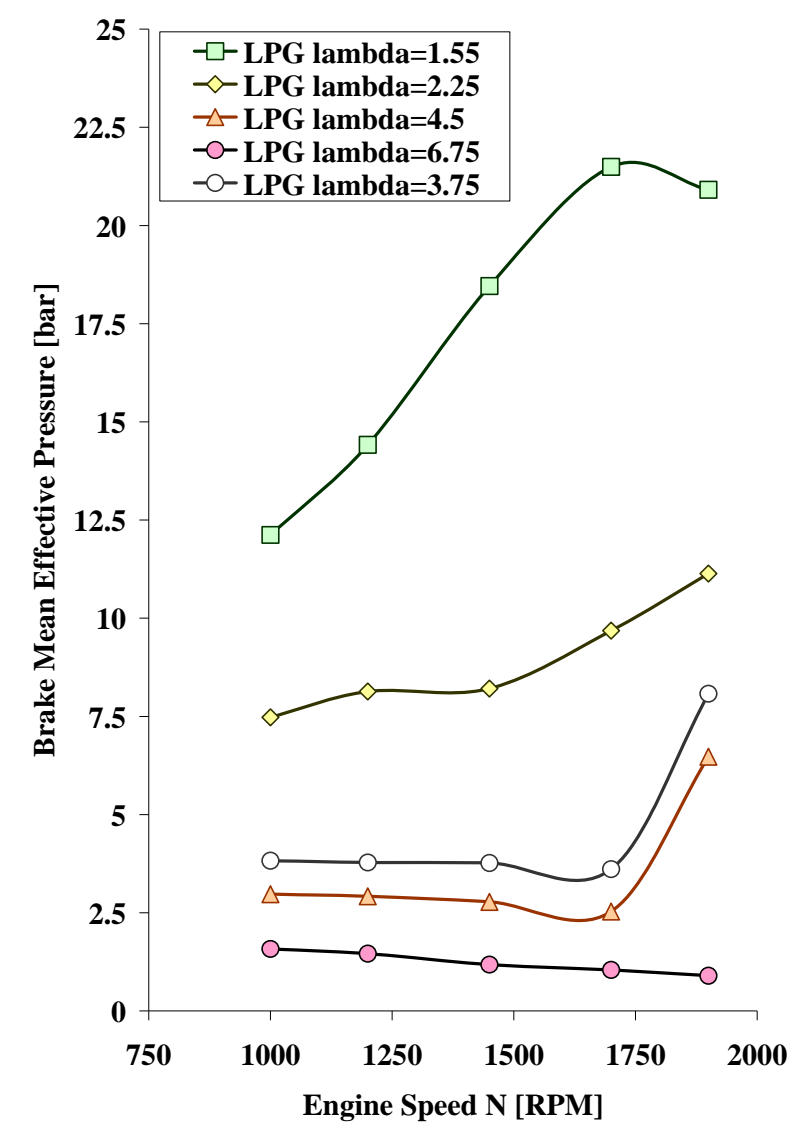

Figure $6 b$ - Computed brake mean effective pressure for the LPG fuelled truck engine with variable $\lambda$ 1.55 to 6.75 .

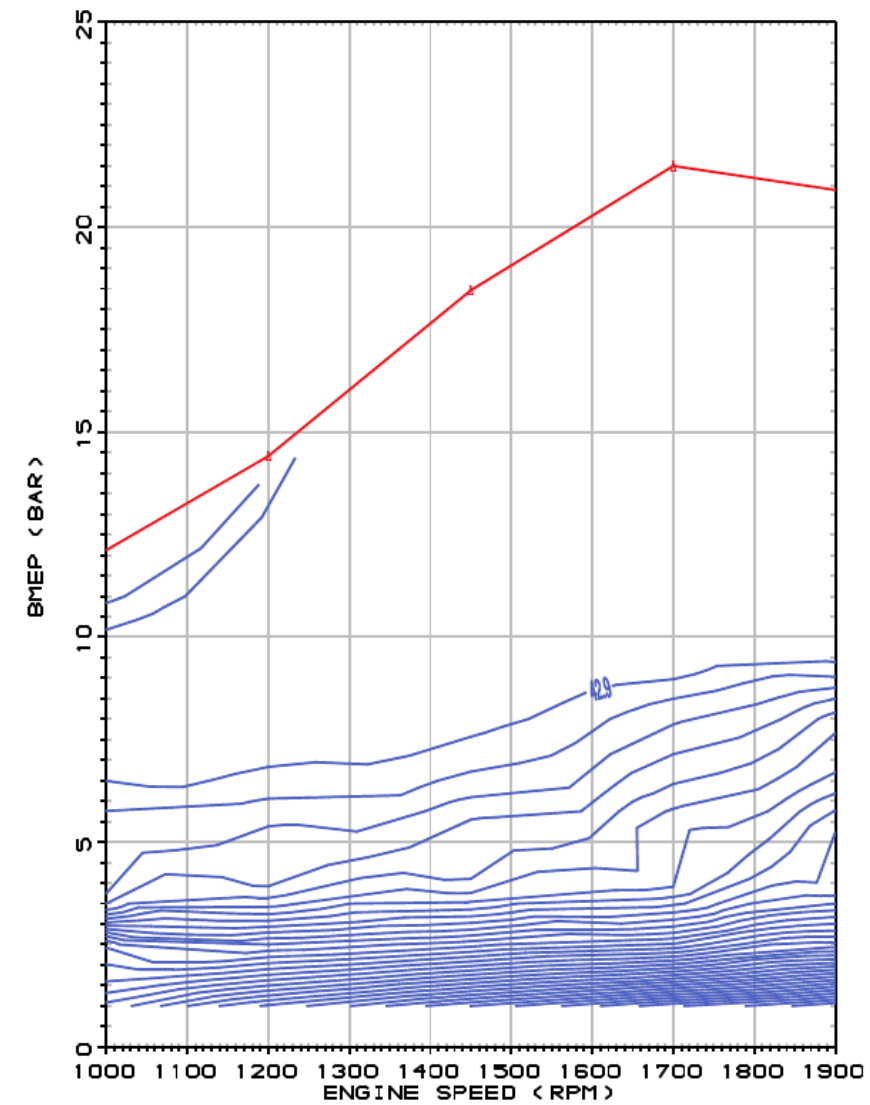

Figure $7 \mathrm{a}$ - Computed brake efficiency $(\mathrm{g} / \mathrm{kWh})$ vs. brake mean effective pressure and engine speed for the LPG fuelled truck engine. 


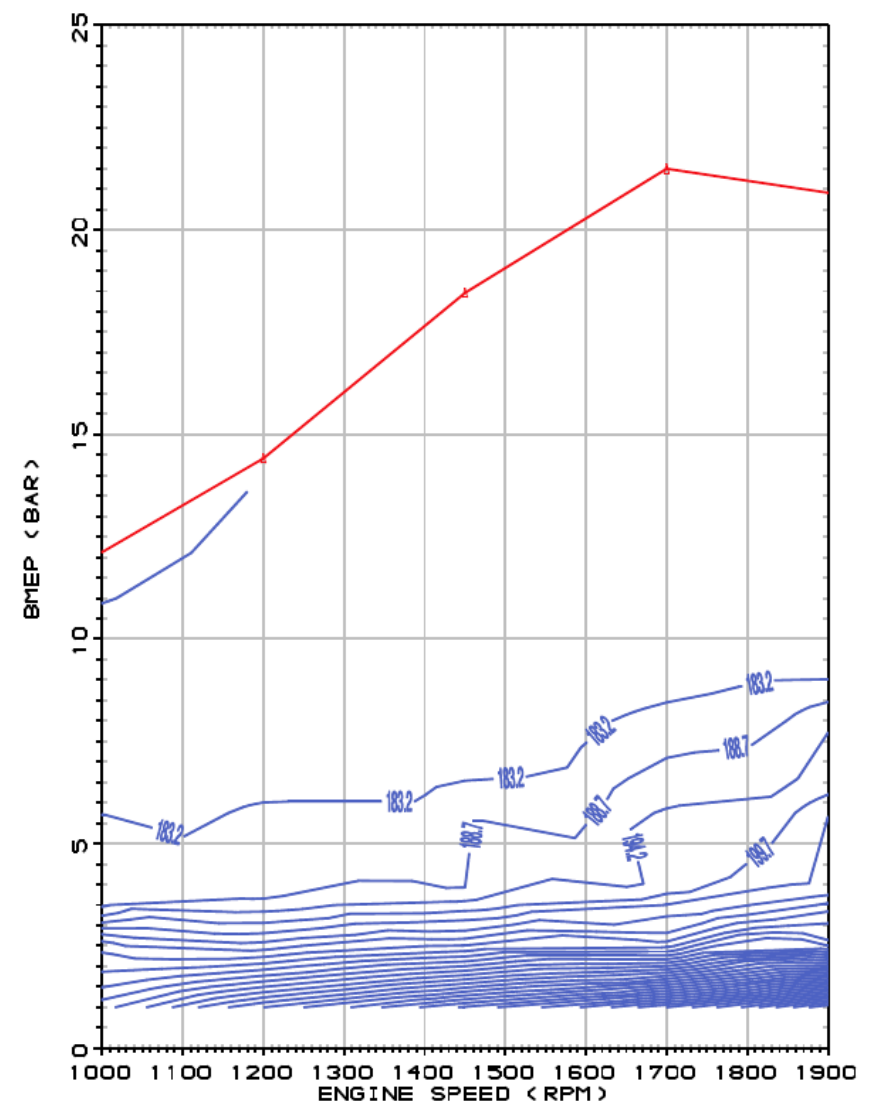

Figure $7 \mathrm{~b}$ - Computed BSFC ( $\mathrm{g} / \mathrm{kWh})$ vs. brake mean effective pressure and engine speed for the LPG fuelled truck engine.

\section{SIMULATIONS OF HDT VEHICLE PERFORMANCE}

Results of vehicle fuel economy have then been obtained with a vehicle model (Lotus Vehicle [35]). The truck is a front axle refuse truck powered by an 11TDI Diesel engine modified to LPG with an 8-Speed transmission to the rear axle of Ratios 17.77 Low to 0.71 High. Basic data of the engine are those in the previous paragraph. Basic data of the vehicle are presented in Table 2.

\begin{tabular}{|c|c|}
\hline Weight $[\mathrm{kg}]$ & 10,950 \\
\hline Frontal Area $\left[\mathrm{m}^{2}\right]$ & 4.75 \\
\hline Drag Coefficient & 0.74 \\
\hline Tyre Rolling Radius [m] & 0.54 \\
\hline Final Drive Ratio & 5 \\
\hline Gearbox & Manual \\
\hline Number of ratios & 8 \\
\hline Gear. 1 Ratio & 17.7 \\
\hline Gear. 2 Ratio & 10.94 \\
\hline Gear. 3 Ratio & 6.57 \\
\hline Gear. 4 Ratio & 4.05 \\
\hline Gear. 5 Ratio & 2.54 \\
\hline Gear. 6 Ratio & 1.57 \\
\hline Gear. 7 Ratio & 1 \\
\hline Gear. 8 Ratio & 0.71 \\
\hline
\end{tabular}

Table2 - Basic vehicle data.

The Brake Specific Fuel Consumption (BSFC) vs. Brake Mean Effective Pressure (BMEP) and engine speed is the one presented in figure $7 \mathrm{~b}$. Current regulations do not require complete heavy-duty Diesel and gas vehicles to be chassis certified, instead requiring certification of their engines [42-45]. Many driving cycles have been proposed to represent real world driving for emissions and fuel consumption testing. However, these cycles are not part of current emission regulations and their validity is not globally recognized. The World-Wide Harmonized Heavy-Duty Certification (WHDC) Procedure applies to Diesel and gas engines (natural gas or LPG) [42-45] tested on engine dynamometers. WHDC is based on the world-wide pattern of real non hybrid heavy commercial vehicle use. 
Because the WHDC discussed above is an engine dynamometer test and not a chassis dynamometer test, first simulations have been performed considering a version of the hot ECE+EUDC cycle modified for top velocity $80 \mathrm{~km} / \mathrm{h}$ as more reasonable for a heavy duty truck of almost $11,000 \mathrm{~kg}$ weight. The special hot ECE+EUDC velocity scheduled is shown in Figure $8 \mathrm{a}$.

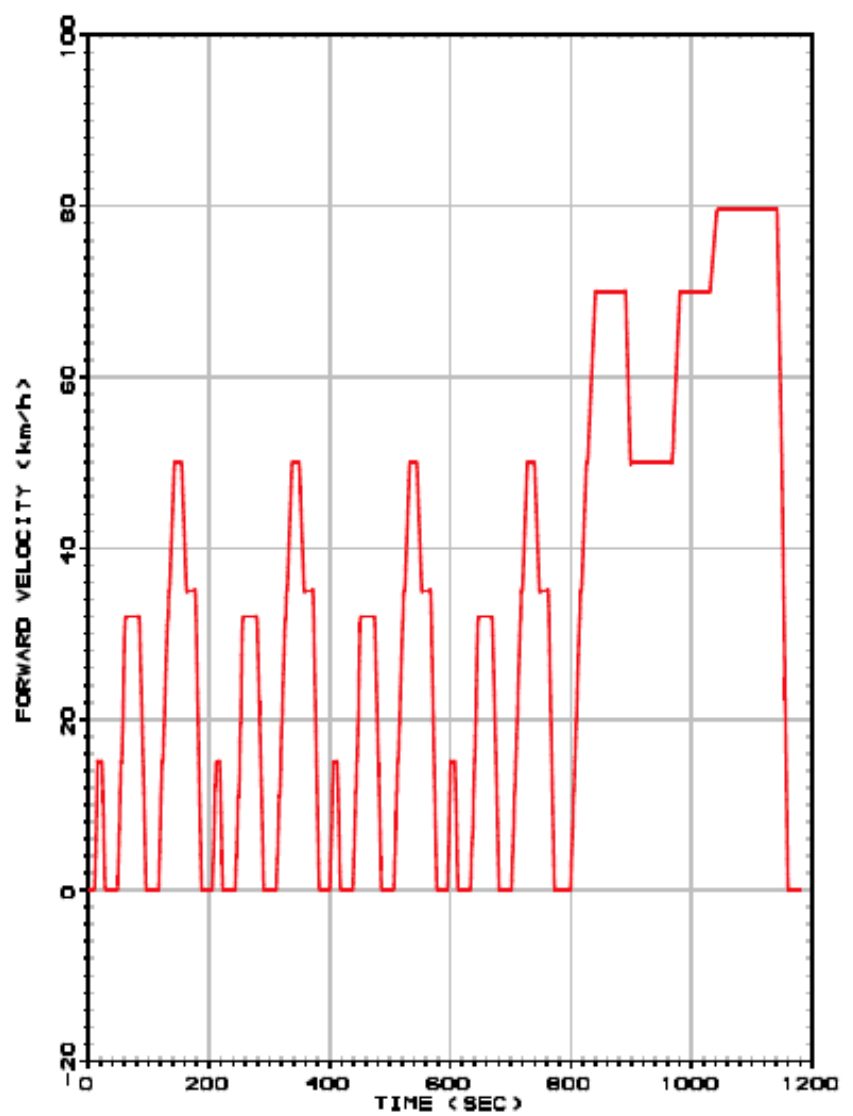

Figure $8 \mathrm{a}$ - Modified ECE+EUDC velocity schedule for fuel consumption of heavy duty trucks.

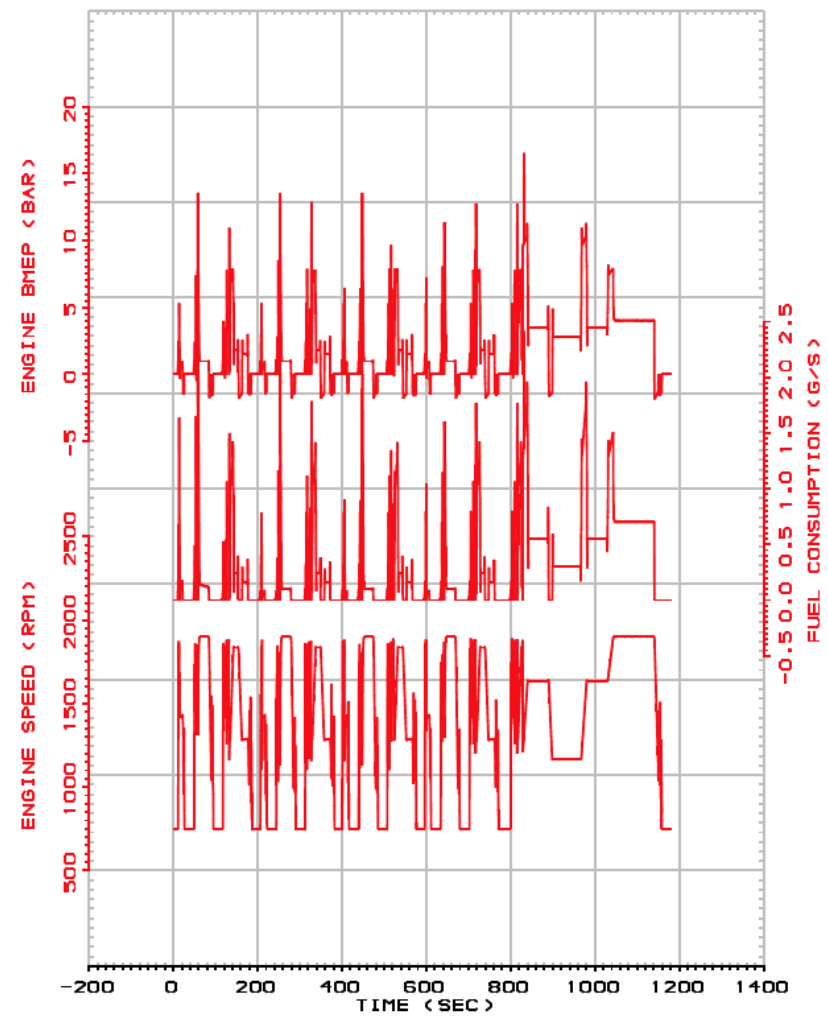

Figure $8 b-$ Hot modified ECE+EUDC computational results. 
Figure $8 \mathrm{~b}$ presents the computed brake mean effective pressure, speed and fuel consumption over the hot ECE+EUDC cycle. The shift schedule is set to use the engine in between $1,200 \mathrm{rpm}$ and 1,800 rpm. The 11TDI LPG engine requires $2366 \mathrm{~g}$ of LPG fuel having specific gravity of 0.5 and lower heating value of $46.55 \mathrm{MJ} / \mathrm{Kg}$ for the test, corresponding to a fuel consumption of 45.4 litres per $100 \mathrm{~km}$. The overall cycle efficiency is $30.4 \%$. The baseline 11TDI Diesel engine requires $2853 \mathrm{~g}$ of Diesel fuel having specific gravity 0.84 and lower heating value of $44 \mathrm{MJ} / \mathrm{Kg}$ for the test, corresponding to a fuel consumption of 31.1 litres per $100 \mathrm{~km}$. The overall cycle efficiency for the Diesel is $31.2 \%$. The overall cycle efficiencies of the Diesel and LPG engines are therefore very close, with differences well below the limits of accuracy of the coupled computational methods for engine and vehicle.

\section{CONCLUSION}

Development of a jet ignition pre-chamber is central to the development of always lean burn engines, where the load can be controlled by the quantity of fuel injected within the main chamber by a direct injector then bulk ignited by multiple jets of hot reacting gases.

Standalone pre-chamber and pre-chamber plus in-cylinder CFD simulations and CAE engine simulations as well as the analogous experiments should all be considered in the development of the many devices comprised in the DI-JI engine concept because of their complementarities and different level of complexity and details.

The jet ignition pre-chamber has many advantages over a standard spark plug main chamber ignition. This ignition system can be used with or without direct injection, in the latter case to burn mixtures much leaner or just to burn quicker same mixtures with larger bores. Coupled with direct injection it allows bulk ignition of stratified mixtures, and therefore bulk combustion far from the solid boundaries, thus avoiding large heat losses. High energy ignition by a large quantity of hot partially burned combustion products in multiple locations across the main combustion chamber greatly enhances the rate of combustion when reference is made to a standard point wise limited energy spark ignition.

With careful optimizing of main chamber injector location and geometric and operation parameters, in cylinder geometry including bowl in piston shape, ignition pre-chamber injector location and geometric and operation parameters, ignition pre-chamber spark plug location, ignition pre-chamber geometry and location with reference to the in cylinder also including number and orientation of nozzles, the system may produce an extremely efficient combustion over the full range of engine loads as well as a significant increase of top brake efficiencies of flame front propagating engines.

New engines fully designed to accommodate direct injection and jet ignition may have efficiencies exceeding $50 \%$ running lean with propane and hydrogen fuels. Conversion of existing Diesel truck engines to run propane fuels with replacement of the Diesel direct injector with the direct injector of LPG and a jet ignition pre-chamber may improve efficiencies up to $2 \%$ at high speed, and permit brake efficiencies $42-44 \%$ all over the range of engine speed from one third to full load.

With reference to port fuel injected and standard spark plug ignited conversion of Diesel engines to LPG, the direct injection jet ignition engine concept has the advantage of the much more efficient load control by quantity of fuel injected permitted by the ability to burn much leaner mixtures, as well as of larger top efficiencies permitted by the bulk combustion process.

Benefits of the technology includes reduced greenhouse and other emissions and reduced consumption as well as encourage the increased uptake of alternative fuels, thus potentially enhancing national energy security and reducing greenhouse gas emissions. The work is still in progress. It is aimed at reducing and capturing emissions in transport and energy generation, with particular emphasis to conversion of high duty Diesel engines to run gaseous fuels, with goal achieving Euro 6 emission standards without after treatment (but obviously much different specific power of the thermal engine). Exhaust energy recovery, heat insulation, engine buffering, charge cooling and cooled exhaust gas recirculation not considered here may be relevant to achieve better efficiencies while meeting Euro 6 emission standards.

The Author has been involved in the past in other R\&D activities having had in the beginning less brilliant perspectives than the coupling of direct injection and jet ignition, namely the revolutionary FIAT Uni-jet Diesel common rail direct injection system that changed the passenger car market in Europe during the 90s, or the FIAT Multi-Air pneumatic valve actuation system that is now the first fully variable hydraulic valve actuation system in production. It is the Author's opinion that it is more the current financial melt down than the technical challenges or limitations for coupling of direct injection and jet ignition which prevent it to be realized currently.

The Direct Injection Jet Ignition engine concept suffers from the unavailability of funds to prototype parts and to carry out experiments. Considering the patents on the miniaturized jet ignition device as well as on the coupling of the jet ignition device with direct injection are lapsed, the proposed technology is certainly worth the effort to invest by OEM or their suppliers. 


\section{ACKNOWLEDGMENTS}

Authors wish to thank Tom Morel, of Gamma Technologies Inc. (GTI), Angelo Tempia of Robert Bosch (Australia) Pty Ltd, and Peter Ewing of VETA Pty Ltd and CD-ADAPCO Australia for the support provided.

\section{REFERENCES}

1. Australian Government Bureau of Infrastructure, Transport and Regional Economics, "Information sheet 34 - Road and rail freight: competitors or complements", DOTARS ID 08470, ISSN 1836-697X, July 2009.

http://www.bitre.gov.au/publications/23/Files/IS34_RoadRailFreight.pdf

2. Australian Government Department of Climate Change, “Australia's National Greenhouse Gas Inventory: Update Quarterly Estimates of Australia's National Inventory: March Quarter 2009"

http://www.climatechange.gov.au/inventory/2007/pubs/quarterly-updatenggi.pdf

3. Australian Government, Department of the Environment, Water, Heritage and the Arts, "Life-cycle Emissions Analysis of Alternative Fuels for Heavy Vehicles - Stage 1", March 2000.

http://www.environment.gov.au/settlements/transport/publications/pubs/lifecycle.pdf

4. Australian Government, Department of the Environment, Water, Heritage and the Arts publication "Comparison of Transport Fuels Final Report (EV45A/2/F3C) to the Australian Greenhouse Office on the Stage 2 study of Life-cycle Emissions Analysis of Alternative Fuels for Heavy Vehicles".

http://www.environment.gov.au/settlements/transport/comparison/pubs/comparison.pdf

5. US Department of energy, Energy efficiency and renewable energy, vehicle technology program, "FY 2008 Progress report For Advanced combustion engine technologies".

http://www1.eere.energy.gov/vehiclesandfuels/pdfs/program/2008_adv_combustion_engine.pdf

6. http://www.delphi.com/pdf/emissions/Delphi-Heavy-Duty-Emissions-Brochure-2009.pdf

7. A. A. Boretti, H. C. Watson, Lean burn direct injection jet ignition internal combustion engine, IP Australia Provisional Patent Application SPEP-11865853 (2009901639) of April 17, 2009.

8. A. A. Boretti, H. C. Watson, Lean burn direct injection jet ignition internal combustion engine without spark plug, IP Australia Provisional Patent Application SPEP-11928154 (2009901961) of May 5, 2009.

9. http://webbook.nist.gov/ (retrieved July 6, 2010)

10. http://delphi.com/shared/pdf/ppd/pwrtrn/gas_multec_gdifsc.pdf (retrieved July 6, 2010)

11. http://www.vdo.com/NR/rdonlyres/4AE2AE7D-EEA1-4D8C-B5C8-5BAD75A5B1CD/0/PT_Bro_EN_Final_160408.pdf (retrieved July 6, 2010)

12. http://www.hoerbiger.com/Niche-Automotive-Applications.10762.0.html (retrieved July 6, 2010)

13. R. Heindl, H. Eichlseder, C. Spuller, F. Gerbig and K. Heller, "New and Innovative Combustion Systems for the H2-ICE: Compression Ignition and Combined Processes", paper presented to the 2009 SAE World Congress, Detroit, Michigan, USA, April 20-23, 2009. SAE P. 2009-01-1421.

14. http://delphi.com/shared/pdf/ppd/pwrtrn/gas_multecdig_hom.pdf (retrieved July 6, 2010)

15. A. A. Boretti, H. C. Watson, Development of a direct injection high efficiency liquid phase LPG spark ignition engine, paper published in the SAE 2009 International Power trains, Fuels and Lubricants Meeting, Florence, Italy, June 15-17, 2009. SAE P. 2009-01-1881.

16. A. A. Boretti, H. C. Watson, Development of a direct injection high flexibility CNG/LPG spark ignition engine, paper published in the SAE 2009 International Power trains, Fuels and Lubricants Meeting, Florence, Italy, June 15-17, 2009. SAE P. 2009-011969.

17. A. Boretti, H. C. Watson, "The lean burn direct-injection jet-ignition turbocharged liquid phase LPG engine", paper presented to the 15th Asia Pacific Automotive Engineering Conference (APAC-15), Hanoi, Vietnam, October 2009.

18. A. Boretti, H. C. Watson, "The lean burn direct-injection jet-ignition gas engine", International Journal of Hydrogen Energy vol. 34 (2009) pp. 7835 - 7841, doi:10.1016/j.ijhydene.2009.07.022.

19. A. Boretti, H. C. Watson, "The lean burn direct-injection jet-ignition flexi gas fuel LPG/CNG engine", paper presented to the 2009 SAE Power trains, Fuels and Lubricants Meeting, San Antonio, Texas, USA, November 2009. SAE P. 2009-01-2790.

20. A. Boretti, H. C. Watson, A. Tempia, "Computational analysis of the lean burn direct-injection jet-ignition hydrogen engine", Proceedings of the Institution of Mechanical Engineers, Part D: Journal of Automobile Engineering, Vol. 224 (2009), doi: 10.1243/09544070jauto1278.

21. http://www.ngksparkplugs.com/images/pdfs/racing_catalog.pdf (retrieved July 6, 2010)

22. http://www.cd-adapco.com/products/STAR-CCM_plus/ (retrieved July 6, 2010)

23. http://www.gtisoft.com/broch_gtpower.html (retrieved July 6, 2010)

24. Lumsden G., Watson H.C., Glasson N., Chow C. and Chalko T., "Observations of Hydrogen Assisted Jet Ignition", Proceedings of Hydrogen Power Thermal \& Electrochemical Systems International Symposium, Italy, June 1995.

25. Lumsden G. and Watson H.C., "Optimum Control of an S.I. engine with a $\lambda=5$ capability", SAE P.950689.

26. Lumsden G. and Watson H.C., "HAJI Operation in a Hydrogen-only mode for Emission Control at Cold Start", SAE P.950412. 
27. Lawrence, J., "Hydrocarbon Emission from a HAJI Equipped Ultra Lean Burn Engine”, University of Melbourne PhD Thesis, Parkville, Melbourne, Australia, 1999.

28. Dober, G., "Geometric Control of HC emissions", University of Melbourne PhD Thesis, Parkville, Melbourne, Australia, 2002.

29. Hamori, F., "Optimising the application of HAJI to the supercharged engine", University of Melbourne PhD Thesis, Parkville, Melbourne, Australia, 2006.

30. Mehrani, P., "Flame Propagation and Knocking in a HAJI Engine", University of Melbourne PhD Thesis, Parkville, Melbourne, Australia, 2008.

31. http://www.ricardo.com/en-gb/Software/Productoffering--description/WAVE1/ (retrieved July 6, 2010)

32. Harry Lehtiniemi, "Efficient Engine CFD with Detailed Chemistry”, ERC 2007 Symposium "Future Fuels for IC Engines", June 6-7, 2007, Madison, WI.

http://www.erc.wisc.edu/documents/symp07-Lehtiniemi.pdf (retrieved July 6, 2010)

33. http://www.diganars.com/about.html (retrieved July 6, 2010)

34. http://www.ngk.de/Glow_plugs.687.0.html (retrieved July 6, 2010)

35. http://www.lesoft.co.uk/index1.html (retrieved January 8, 2010)

36. A.A. Boretti, "Modelling auto ignition of hydrogen in a jet ignition pre-chamber" International Journal of Hydrogen Energy 35 (2010) 3881-3890.

37. A.A. Boretti, "Vehicle driving cycle performance of the spark-less di-ji hydrogen engine" International Journal of Hydrogen Energy 35 (2010) 4702-4714.

38. http://www.wps.com/LPG/WVU-review.html (retrieved July 6, 2010)

39. http://www.environment.gov.au/atmosphere/fuelquality/publications/pubs/lpg-fuel-quality-standard-discussion-paper.pdf (retrieved July 6, 2010)

40. http://www.environment.gov.au/atmosphere/fuelquality/publications/pubs/paper5.pdf (retrieved July 6, 2010)

41. http://www.afdc.energy.gov/afdc/progs/fuel_compare.php (retrieved July 6, 2010)

42. www.unece.org/trans/doc/2003/wp29grpe/TRANS-WP29-GRPE-46-inf04e.pdf (retrieved April 1, 2010).

43. www.unece.org/trans/doc/2001/wp29grpe/TRANS-WP29-GRPE-41-inf01.pdf (retrieved April 1, 2010).

44. www.Dieselnet.com/standards/cycles/whtc.php (retrieved April 1, 2010).

45. www.Dieselnet.com/standards/cycles/whsc.php (retrieved April 1, 2010).

46. A. Boretti, H. Watson, "Numerical study of a turbocharged, jet ignited, cryogenic, port injected, hydrogen engine", paper presented to the 2009 SAE World Congress, Detroit, Michigan, USA, April 20-23, 2009. SAE P. 2009-01-1425. Included in SAE book “Hydrogen IC Engines, 2009”, ISBN 978-0-7680-2147-9, April 2009.

\section{NOMENCLATURE}

ADR Australian Design Rule

BITRE Australian Government's Bureau of Infrastructure, Transport and Regional Economics

BMEP Brake Mean Effective Pressure

BSFC Brake Specific Fuel Consumption

CAE Computer Aided Engineering

CAD Computer Aided Design

CFD Computational Fluid Dynamic

CNG Compressed Natural Gas

DI Direct Injection

EBU Eddy Break-Up

ECE Economic Commission for Europe

EGR Exhaust Gas Recirculation

EUDC Extra Urban Driving Cycle

GHG Green House Gases

HDT Heavy Duty Truck

HP High Pressure

ICE Internal Combustion Engines

JI Jet Ignition

LP Low Pressure

LPG Liquefied Petroleum Gas

LTC Low Temperature Combustion

MON Motor Octane Number

NEDC New European Driving Cycle

OBD On Board Diagnostic

ODE Ordinary Differential Equations

OEM Original Equipment Manufacture

PDE Partial Differential Equations 
PEMS Portable Emission Measurement System

PFI Port Fuel Injection

PM Particulate Matter

R\&D Research and Development

RON Research Octane Number

SOC Start of Combustion

TDC Top Dead Centre

TDI Turbo Direct Injection

WHDC World-Wide Harmonized Heavy-Duty Certification 


\section{APPENDIX}

\begin{tabular}{|c|c|c|c||}
\hline Component & Formula & Research Octane Number & Motor Octane Number \\
\hline propane & $\mathrm{C}_{3} \mathrm{H}_{8}$ & 111.5 & 100 \\
\hline n-butane & $\mathrm{C}_{4} \mathrm{H}_{10}$ & 95 & 92 \\
\hline isobutane & $\mathrm{C}_{4} \mathrm{H}_{10}$ & 100.4 & 99 \\
\hline propylene & $\mathrm{C}_{3} \mathrm{H}_{6}$ & 100.2 & 85 \\
\hline n-butane-1 & $\mathrm{C}_{4} \mathrm{H}_{10}$ & 100 & 80 \\
\hline n-butane-2 & $\mathrm{C}_{4} \mathrm{H}_{10}$ & 101 & 83 \\
\hline
\end{tabular}

Table A1 - LPG components Research and Motor Octane Numbers

\begin{tabular}{|c|c|c|c|c|}
\hline FUEL & Gasoline & Ethanol & Methanol & Propane \\
\hline Chemical formula & $\mathrm{C} 4$ to $\mathrm{C} 12$ & $\mathrm{C}_{2} \mathrm{H}_{5} \mathrm{OH}$ & $\mathrm{CH}_{3} \mathrm{OH}$ & $\mathrm{C}_{3} \mathrm{H}_{8}$ \\
\hline Molecular Weight & $100-105$ & 46.07 & 32.04 & 44.1 \\
\hline \multicolumn{5}{|l|}{ Composition, \% Weight [\%] } \\
\hline $\begin{array}{ll}\text { o } & \text { Carbon }\end{array}$ & $85-88$ & 52.2 & 37.5 & 82 \\
\hline $\begin{array}{ll}\text { O Hydrogen } \\
\end{array}$ & $12-15$ & 13.1 & 12.6 & 18 \\
\hline $0 \quad$ Oxygen & 0 & 34.7 & 49.9 & 0 \\
\hline Lower Heating Value (LHV) $[\mathrm{MJ} / \mathrm{Kg}]$ & 43.440 & 26.947 & 20.090 & 46.287 \\
\hline Stoichiometric air/fuel weight & 14.70 & 9.00 & 6.45 & 15.70 \\
\hline Stoichiometric fuel/air weight & 0.068 & 0.111 & 0.155 & 0.064 \\
\hline Energy per $\mathrm{kg}$ of stoichiometric mixture $[\mathrm{MJ} / \mathrm{Kg}]$ & 2.767 & 2.695 & 2.697 & 2.772 \\
\hline Research Octane Number (RON) & 95 & 129 & 133 & 112 \\
\hline Latent Heat of vaporization @ $274 \mathrm{~K}[\mathrm{~kJ} / \mathrm{kg}]$ & 348.9 & 921.1 & 1177.0 & 449.2 \\
\hline $\begin{array}{l}\text { Amount of energy available per kg of stoichiometric mixture to cool the } \\
\text { charge }[\mathrm{kJ} / \mathrm{kg}]\end{array}$ & 22.2 & 92.1 & 158.0 & 26.9 \\
\hline Auto ignition temperature $[\mathrm{K}]$ & 516.2 & 681.7 & 722.8 & 708.9 \\
\hline \multicolumn{5}{|l|}{ Flammability limits, volume [\%] } \\
\hline o Lower & 1.4 & 4.3 & 7.3 & 2.2 \\
\hline o Higher & 7.6 & 19.0 & 36.0 & 9.5 \\
\hline Specific heat, $[\mathrm{KJ} / \mathrm{Kg} \mathrm{K}]$ & 2.010 & 2.386 & 2.512 & - \\
\hline Volume $\%$ fuel in vaporized stoichiometric mixture [\%] & 2.00 & 9.00 & 6.45 & - \\
\hline Boiling temperature $[\mathrm{K}]$ & $285.6-483.9$ & 336.7 & 323.9 & 216.7 \\
\hline Flash point, closed cup [K] & 216.2 & 271.7 & 270.0 & 154.5 \\
\hline Surface tension @ 293 K [mN/m] & $20.14-21.62$ & 22.39 & 22.50 & - \\
\hline Viscosity@ $278.9 \mathrm{~K}\left[\mathrm{~mm}^{2} / \mathrm{s}\right]$ & $0.5-0.6$ & 1.5 & 0.74 & - \\
\hline Specific gravity@274 K & $0.75(0.72-0.78)$ & 0.794 & 0.796 & 0.508 \\
\hline Laminar flame speed @ 1 bar and 300K [cm/s] & 33 & 41 & 50 & - \\
\hline
\end{tabular}

Table A2 - Parameters of gasoline, ethanol, methanol and propane fuels. 